\title{
Molecular Detection \\ and Quantification of Pythium Species: \\ Evolving Taxonomy, New Tools, and Challenges
}

\author{
Kurtis L. Schroeder \\ Department of Plant Pathology, Washington State University, Pullman, WA \\ Frank N. Martin \\ USDA-ARS, Salinas, CA \\ Arthur W. A. M. de Cock \\ CBS-KNAW Fungal Biodiversity Centre, Utrecht, The Netherlands \\ C. André Lévesque and Christoffel F. J. Spies \\ Agriculture and Agri-Food Canada, Central Experimental Farm, Ottawa, ON \\ Patricia A. Okubara and Timothy C. Paulitz \\ USDA-ARS, Root Disease and Biological Control Research Unit, Pullman, WA
}

\begin{abstract}
The genus Pythium is one of the most important groups of soilborne plant pathogens, present in almost every agricultural soil and attacking the roots of thousands of hosts, reducing crop yield and quality. Most species are generalists, necrotrophic pathogens that infect young juvenile tissue. In fact, Cook and Veseth (29) have called Pythium the "common cold" of wheat, because of its chronic nature and ubiquitous distribution.
\end{abstract}

Pythium is a genus in the Kingdom Chromista or Straminipila (=stramenopiles) and the class or subphylum Oomycota (=oomycetes), depending on the classification schemes $(4,69)$. The authors of this review prefer to continue using the well-established names Oomycetes or Oomycota instead of Peronosporomycetes (for explanation see reference 87). Pythium is in the same order as the genus Phytophthora (Peronosporales), whose members are heterotrophic, filamentous, multicellular organisms. Oomycetes are distinct from the true Fungi (Kingdom Eumycota) in several ways. They contain cellulose and $\beta$-glucans in their cell walls, have coenocytic hyphae, produce biflagellate zoospores, with tinsel and whiplash flagella, and have a diploid vegetative state, with meiosis occurring in gametangia (oogonia and antheridia). Oomycetes are phylogenetically related to diatoms and brown algae. As of 2004, 106 species of Pythium had been included by Lévesque and de Cock (90), but close to 300 species have been proposed in the literature according to MycoBank (http://www.mycobank.org), although many of these are not valid or are of doubtful identity (see reference 173 for partial list).

This genus occupies a variety of ecological niches and life styles. They are common in terrestrial habitats, found in soils in both natural (grassland, forest) and agricultural ecosystems around the world. They also occupy aquatic ecosystems such as freshwater lakes and streams (124) and irrigation systems (57). Many are soil saprophytes (107), but a large number are pathogens of plants. Some species also attack mammals (P. insidiosum, 137), fish (116), and algae ( $P$. porphyrae, 67). Some are mycoparasites on other Oomycetes and fungi (141). Most plant-pathogenic species have wide host ranges (e.g., P. ultimum with 719 host records, 38), but some are restricted to certain taxa (e.g., P. graminicola and $P$.

Corresponding author: Timothy C. Paulitz, E-mail: paulitz@wsu.edu

http://dx.doi.org/10.1094/PDIS-03-12-0243-FE

This article is in the public domain and not copyrightable. It may be freely reprinted with customary crediting of the source. The American Phytopathological Society, 2013. arrhenomanes on Poaceae). Pythium spp. are considered necrotrophic pioneer colonizers that attack young feeder roots and germinating seeds and seedlings. They cause pre- and postemergence damping-off by attacking the embryo, hypocotyl, and emerging radicle. Pythium spp. can cause reductions in plant stands in the field and major losses in the greenhouse industry in the production of transplants. On mature plants, the reduction in root biomass, fine feeder roots, and root hairs causes stunting and symptoms of nutrient deficiency aboveground, and significant reductions in yield. On fruit trees, Pythium spp. have been implicated in replant declines when young trees are replanted on a site where an old tree was removed (113). Under wet conditions, Pythium spp. can infect succulent fruits aboveground, causing rots on melons, peppers, and cucumbers. Pythium spp. can also attack bulbs and root crops belowground, such as potato, sugar beets, and carrots.

Many diseases caused by Pythium spp. are favored by wet, cool conditions, although some species are more commonly encountered under warmer conditions (e.g., $P$. aphanidermatum and $P$. myriotylum). Pythium spp. can survive under adverse conditions (dry, cold, heat) as thick-walled oospores. In only a few species, thick-walled chlamydospores can also serve this function (e.g., $P$. tracheiphilum and $P$. dimorphum). Oospores of some species can germinate to form sporangia. Under wet, cool conditions, most Pythium spp. can form sporangia. Sporangia develop a discharge tube through which the cytoplasm flows out to form a vesicle at the tip surrounded by a membrane. Inside the vesicle, the cytoplasm of the sporangia differentiates into zoospores, which are released at maturity by disruption of the membrane (Fig. 1). In contrast, Phytophthora species do not produce vesicles before releasing zoospores. Zoospores move via flagella in the soil water profile and water films around soil particles, and are chemotactically attracted to exudates from roots and germinating seeds, where they encyst, form cell walls, and initiate an infection. The pathogen penetrates epidermal cells by producing cell-wall-degrading enzymes, and kills the tissue ahead of the advancing hyphae by producing enzymes and toxins. Once the tissue is killed and colonized by Pythium, the pathogen sporulates and produces either sporangia or the sexual reproductive structures oogonia and antheridia. After fertilization of the oogonia by antheridia, thickwalled oospores are produced. Some species infect directly by hyphae produced from oospores or hyphal swellings. "Sporangia" of $P$. ultimum (often referred to as hyphal swellings when these do not produce zoospores) can germinate rapidly (within 4 h) (134), 
have fast hyphal growth rates, and can infect seeds within $24 \mathrm{~h}$ (56). Pythium species can be easily spread in irrigation and hydroponic systems in greenhouses, and can be splashed around to colonize potting mixes and other greenhouse substrates. In the field, they can be moved by irrigation and tillage operations, or carried on planting material such as bulbs.

Where Pythium spp. are the cause of seedling damping-off or emergence reduction, the causal agent can easily be identified based on symptoms and culturing. In more mature plants, however, infection by Pythium spp. is more difficult to diagnose, because of the nonspecific symptoms that could have abiotic causes such as nutrient deficiencies or be due to other root rotting pathogens. Pythium spp. often cause a generalized stunting and yellowing, but unless the grower has a healthy crop for comparison, the damage may not be noticed. Plants can be dug and the root systems examined to look for root pruning, but this is difficult to do in the field, and similar symptoms may be caused by other soilborne pathogens. Individual fields may contain a number of Pythium species (133), and some are more virulent on a specific host than others, which makes diagnosis and disease management recommendations even more difficult. Molecular methods that can accurately identify and quantify this important group are needed for disease diagnosis and management recommendations and to better understand the epidemiology and ecology of this important group.

The purpose of this feature article is to outline the current stateof-the-art in the detection and quantification of this important genus. In addition, we will introduce the reader to new changes in the taxonomy of this group.

\section{Taxonomy, Molecular Phylogeny, and DNA Barcoding of Pythium: New Concepts and Classification}

Taxonomy and classification based on morphology. Pythium species have been traditionally identified and classified based on the morphology of asexual and sexual structures. Primary characters are the shape of the sporangia and the ornamentation of the oogonia. Van der Plaats-Niterink (173) distinguished four types of sporangia: filamentous, either inflated or not, and globose, either internally proliferating or not (Fig. 2). In addition, certain species do not produce sporangia but often develop hyphal swellings. A fifth type of sporangium was observed by Lévesque and de Cock (90) for clade D: contiguous sporangia consisting of (sub-)globose elements that are connected by hyphal segments. Oogonia in Pythium are either smooth-walled or ornamented with spines of different shapes (Fig. 3). Other important characters are whether the oospore completely fills the oogonial cavity (plerotic) or not (aplerotic); the shape, number, and method of attachment of antheridia to oogonia, and the presence of hyphal swellings. The term "hyphal swellings" is used in Pythium for (sub-)globose structures that occur terminally or intercalary in the hyphae and that may or may not be separated from the hyphae by cross walls. Hyphal swellings have walls which are not or only slightly thicker than the

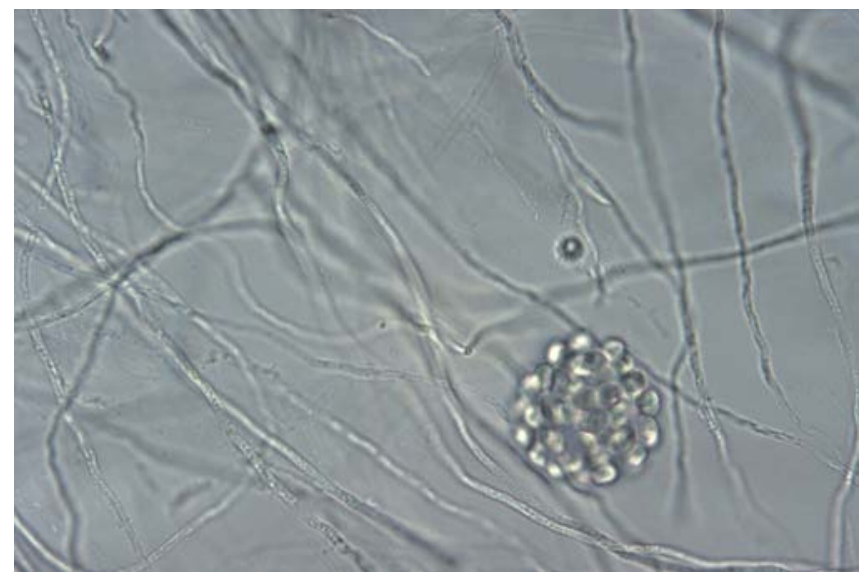

Fig. 1. Zoospore release from a Pythium sp. with filamentous sporangia. hyphal walls. Thick-walled chlamydospores like those in Phytophthora occur only in a few Pythium species.

Taxonomic keys and descriptions have been widely used for identifying Pythium species $(33,112,115,173,183,184)$. The monograph of Van der Plaats-Niterink is the most complete, but is 30 years old. The sexual reproductive structures of Pythium can be formed on a variety of agar media containing C-17 sterols such as cholesterol or stigmasterol, but natural media are most commonly used. Sporangia are commonly formed in both water culture, consisting of a colonized grass blade in water, and agar culture, but
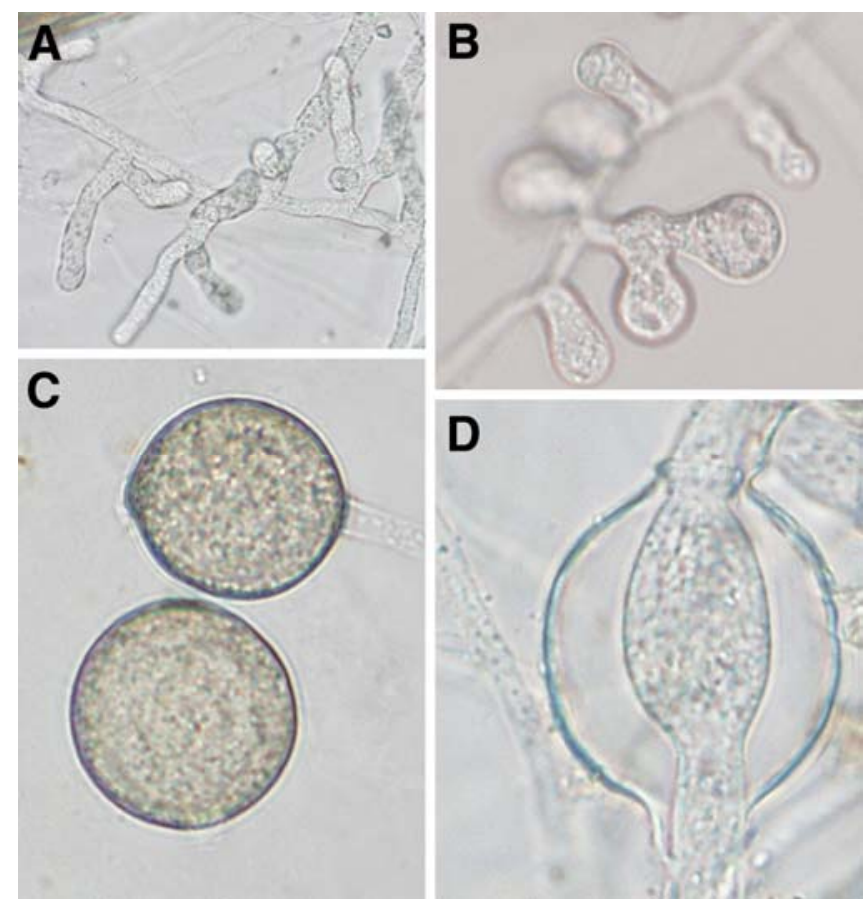

Fig. 2. Sporangia of Pythium. A, Filamentous sporangia of Pythium dissotocum. B, Inflated filamentous (lobed) sporangia of Pythium torulosum. C, Globose hyphal swellings of Pythium ultimum. D, Internally proliferating sporangium of Pythium middletonii.
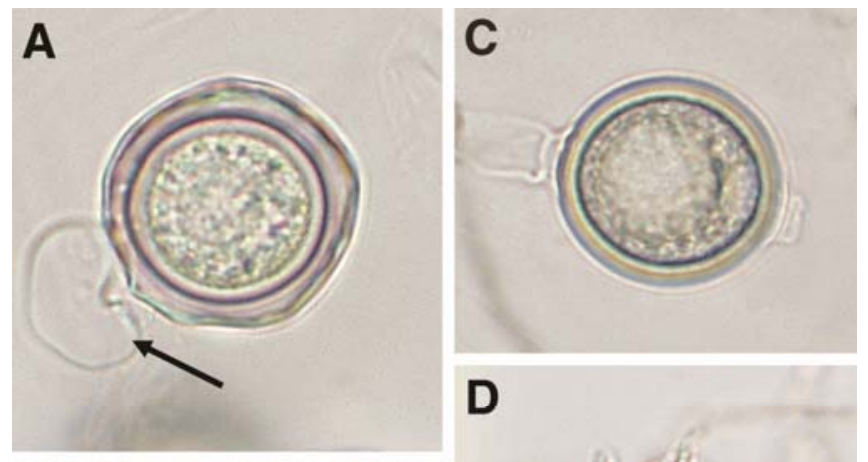

D
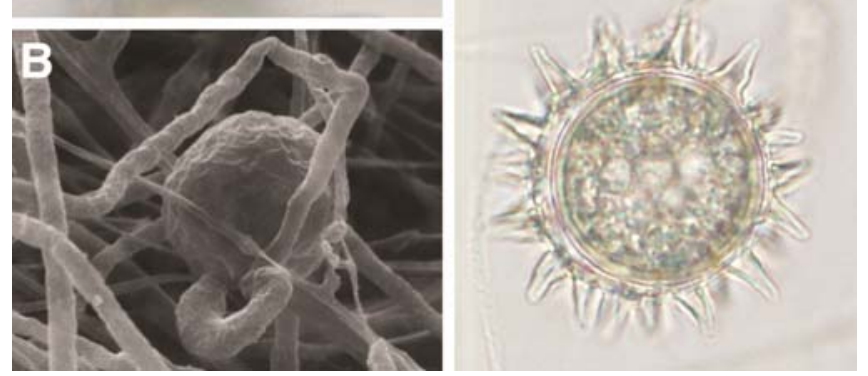

Fig. 3. Oogonia and oospores of Pythium. A, Smooth oogonium of Pythium ultimum, with aplerotic oospore inside and single antheridium (arrow). B, Oogonium and antheridia of $P$. ultimum under scanning electron microscopy. C, Smooth intercalary oogonium of Pythium rostratifingens with plerotic oospore. D, Spiny oogonium of Pythium oligandrum. 
zoospore release is observed only in water culture. Oogonia may be formed in potato-carrot agar or cornmeal agar; however, some species only develop oogonia in water cultures. Most Pythium species are homothallic, but some are heterothallic and require mating of isolates with opposite mating types to produce oospores. Pythium spp. can be isolated from infected roots and other plant parts using selective media containing antibacterial antibiotics such as rifampicin, ampicillin, or penicillin; Rose Bengal and PCNB to slow the growth of fungi; and pimaricin or benomyl to inhibit nonoomycetes. A number of these selective media are described in Martin (101), with a more recent evaluation of fungicides presented in Morita and Tojo (119). Pythium spp. can be isolated from soil using a number of baiting techniques (grass leaves, hemp seed, carrots, potatoes) and quantified from soil using selective media and dilution plating. But quantification of Pythium by dilution plating has a number of drawbacks and limitations. Dilution plating may not accurately detect soil populations below 10 to 50 propagules per gram of soil unless the number of replicated plates per sample is high enough (T. C. Paulitz, unpublished). Slow-growing species also may be overgrown by faster growing species. In addition, oospores are constitutively dormant, and some species may have a low germination rate on the media. But the most important limitation is that not all species can be distinguished on

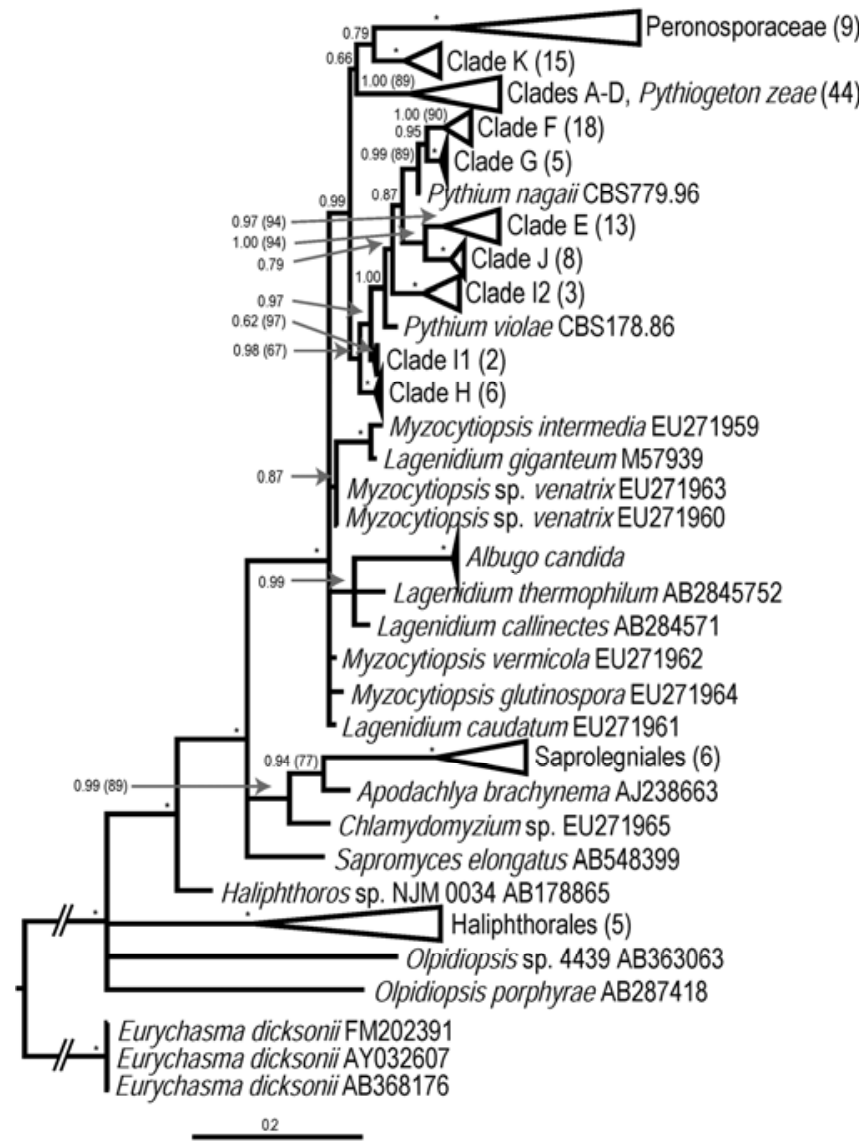

Fig. 4. Phylogeny of Pythium and related oomycetes as inferred from Bayesian analysis of small subunit (SSU) rRNA sequences. This tree represents the consensus between two independent Markov chains run for 11350 cycles (the first 300 cycles were discarded as burn in) under the CATGTR model in PhyloBayes 3.3 (82) with constant characters deleted. Maximum likelihood (ML) analysis was performed in PhyML 3.0 (50) using the best-fit model $(\mathrm{HKY}+\mathrm{i}+\mathrm{g})$ as estimated in Mega 5.05 (165). ML bootstrap support values were calculated from 100 repeats. Bayesian probability support and ML bootstrap support (in brackets) are shown when above 0.60 and $60 \%$ respectively. Asterisks $\left(^{*}\right)$ indicate support of $>0.95$ and $>95 \%$. Clade titles are followed by numbers in brackets indicating the number of species contained in the clade. The alignment for these analyses consisted of 168 sequences of which 47 were obtained from GenBank $(14,34,40,77,152,153$, and some unpublished). Sequence alignments were generated in MAFFT (66) and manually adjusted in BioEdit 7.0.5.3 (51). plates based on their morphology, so different colony types must be subcultured and identified, which is extremely time-consuming and laborious. It may take 2 to 3 weeks for an accurate identification of all species that may be observed on a soil dilution plate.

Molecular phylogeny. The earliest work on molecular phylogeny of Pythium was based on a restriction map of the ribosomal DNA cistron (72). The rDNA was purified by $\mathrm{CsCl}$ ultracentrifugation, and restriction fragment length polymorphism (RFLP) data were analyzed to generate restriction maps of five Pythium species. Between the two species with filamentous sporangia, there was a very high similarity, whereas species with globose sporangia were well separated from those species but with more distance among themselves. The advent of polymerase chain reaction (PCR) amplification and the design of ribosomal DNA primers that could work with oomycetes (186) made DNA sequencing much easier, and several studies on the phylogeny of oomycetes included a few Pythium species $(34,142)$, but their sampling in these studies was not large enough to provide a better understanding of the phylogenetic arrangement within the genus. Briard et al. (21) focused only on Pythium and Phytophthora using the ribosomal large subunit (LSU) and showed that the two Pythium species with filamentous sporangia were different from the five with globose sporangia, whereas P. vexans was different from Pythium and Phytophthora. Similar conclusions were reached by Cooke et al. (30) with three filamentous and three globose Pythium species as well as $P$. vexans as part of their first comprehensive study of Phytophthora species. In a study with 30 Pythium species using the internal transcribed spacer (ITS) of the rDNA, Matsumoto et al. (109) showed that species with filamentous and globose sporangia were phylogenetically separated. Using the cytochrome oxidase 2 (cox2) gene, Martin (103) showed that 60 isolates belonging to 24 species formed three phylogenetic groups; species with filamentous sporangia formed one clade, whereas species with globose sporangia formed two separate clades. Some subclade separations were observed and some species such as $P$. nunn did not cluster with other clades. In a study with over 100 Pythium species using ITS for all species and LSU for $60 \%$ of them, Lévesque and de Cock (90) showed that the genus was highly heterogeneous and formed 11 distinct clades that they labeled $\mathrm{A}$ to $\mathrm{K}$ to avoid confusion with clades 1 to 8 for Phytophthora defined by Cooke et al. (30). The filamentous/globose differentiation was maintained as two separate monophyletic groups, whereas the uniqueness of $P$. vexans because of its Phytophthora-like sporangia with Pythium-like zoospore discharge was now phylogenetically supported for a group labeled as clade K. A phylogenetic study by Villa et al. (176) with 39 Pythium species and based on ITS, $\operatorname{cox} 2$, and $\beta$-tubulin also showed several clades within Pythium, as well as the placement of clade K species as closely related to Phytophthora. Bedard et al. (15) studied the $5 \mathrm{~S}$ gene family organization in a very broad range of Pythium species and found that in general, it supported the clade A to $\mathrm{K}$ phylogeny including the very unique status of clade $\mathrm{K}$.

The paraphyletic nature of Pythium is also supported by phylogenetic analyses of the ribosomal small subunit (SSU) and large subunit LSU regions (Figs. 4 and 5). Phytophthora, downy mildew genera, clade $\mathrm{K}$, and Pythium species with filamentous sporangia (clades A to D) form distinct clades with good support in Bayesian ( $>0.95$ probability) and good to moderately good support in maximum likelihood analyses ( $>89 \%$ bootstrap). Additionally, $P$. apinafurcum (included only in the LSU analyses) seems to represent an additional group related to, but distinct from, clade K (Fig. 5), as was also suggested by Uzuhashi et al. (170). Considerable variation is apparent among the remaining Pythium clades ( $\mathrm{E}$ to $\mathrm{J}$, forming globose sporangia). While clade $\mathrm{H}$ forms a well-supported, distinct clade in both phylogenies $(>0.95$ probability, $>95 \%$ bootstrap), the association of clades E, F, G, I, and J as suggested by Uzuhashi et al. (170) has low bootstrap support $(<60 \%)$ in maximum likelihood analyses of either region. Within this group, some clades do not always have very good support (e.g., clade E in the LSU phylogeny and clade I1 in the SSU phylogeny). This inability of the SSU and LSU regions to adequately resolve phylogenetic 
relationships is even more prominent when considering the Pythium-related genera Lagenidium, Myzocytiopsis, and Albugo. In the SSU phylogeny, Lagenidium, Myzocytiopsis, and Albugo formed an unresolved group basal to Pythium, Phytophthora, and the downy mildews (Fig. 4). Although Albugo forms a separate clade in the LSU phylogeny, Lagenidium remained unresolved (Fig. 5). Interestingly, maximum likelihood analyses of the LSU region clustered Lagenidium into a single clade with good bootstrap support (95\%, phylogram not shown), however this clade did not have topological or probability support in Bayesian analysis. Additional and better markers as well as better sampling of related genera would be needed to clarify the relationships between the different globose sporangium Pythium clades, Lagenidium, Myzocytiopsis, and Albugo.

Identification by DNA sequencing and barcodes. The most accurate approach for identification to species level is obtained by sequencing specific loci and doing BLAST analysis and sequence alignments using a reference database. When doing a sequencebased approach for isolate identification, there are several concepts that should be kept in mind. BLAST analysis provides an e-value score indicating sequence identity with a reference sequence that is based on both matching percentage and length of sequence identity, so rather than drawing conclusions based on the highest evalue score, the sequence homology (percent matching) and sequence alignments should be examined to make sure they represent alignments reflective of the length of the query sequence. Also, it is important to make sure the database of reference sequences used for BLAST uses curated sequences from isolates whose identification has been verified and that the query length does not go beyond the region sequenced in the reference dataset. For example, a BLAST search of an ITS sequence that includes large portions of the flanking subunits may return oomycete sequences with the same flanking regions as highest e-value instead of the sequences that have a $100 \%$ matching ITS without any flanking subunit regions.

Historically, the ITS region of the rDNA has been used for identification of Pythium spp. by sequencing due to the large number of sequences available in public databases as well as the level of interspecific variation observed. However, for some species this region may not be the best choice due to the low level of sequence divergence that may be observed among phylogenetically closely related species or because of intraspecific variation. Alternative loci include the nuclear encoded $\beta$-tubulin or LSU of the rDNA $(90,118,176)$ as well as the mitochondrially encoded cytochrome oxidase 1 ( coxl), cox2, or NADH dehydrogenase subunit 1 (nadl) genes $(103,118,176)$. Recently, Robideau et al. (144) completed a comprehensive ITS and coxl sequence analysis of the genus for the Barcode of Life project using validated cultures that are now providing a comprehensive resource for sequence-based identification of isolates (http://www.boldsystems.org). While there are times where a single locus can be used for isolate identification, ideally two or more should be examined before conclusions on species designations are made. When working with the rDNA region it is important to keep in mind that multiple forms may exist within the same isolate. While this has been predominantly reported for the intergenic spacer (IGS) region $(24,71,99,169)$, it has also been observed in the ITS region of Pythium (102) and the related Phytopythium helicoides and Phytopythium mercuriale as well $(16,64)$.

DNA barcoding, the sequencing of short, standardized DNA targets for identification purposes, should not be confused with phylogenetics. Although these two techniques may appear as very similar endeavors because of similarities in protocols and analyses, their fundamental differences should always be kept in mind. Markers useful for separating species tend to be rather poor in establishing deep phylogenies. The coxl gene is the default DNA barcode in GenBank. A sequence accession can receive the BARCODE keyword if it meets requirements such as linkage to a proper voucher and availability of electropherograms to check sequence quality and ambiguities. The coxl sequences from
Robideau et al. (144) have the BARCODE keyword in GenBank, and once the ITS becomes an approved barcode for oomycetes, the ITS sequences from this publication will also have this designation. Although ITS $(30,90)$ and coxl $(108)$ phylogenies seem to be somewhat robust within an oomycete genus since analyses with other markers supported these phylogenies, beyond the generic level these regions may become problematic for phylogenetic analyses. At higher taxon levels, the ITS region can be impossible to align outside of the $5.8 \mathrm{~S}$ coding gene due to length differences, especially when more distant taxa are included. DNA sequences of coxl suffer from saturation of the third codon position, i.e., the amino acids are so conserved that sequences from distant taxa start to have the third codon position reverting back, creating a significant loss of phylogenetic signal for broader taxonomic analysis (35).

ITS sequences can vary within a strain because of diploidy or polymorphisms among copies of this high copy number locus. Some variation in the copies of several mitochondrial genes within a strain have also been observed in P. ultimum (89), although it remains to be determined if this is commonly observed in mitochondrial genomic sequences of other species (F. Martin, unpublished). Handling such variation within a phylogenetic framework is challenging, but for identification or detection using the coxl or ITS DNA barcodes, it is not a serious issue as long as this

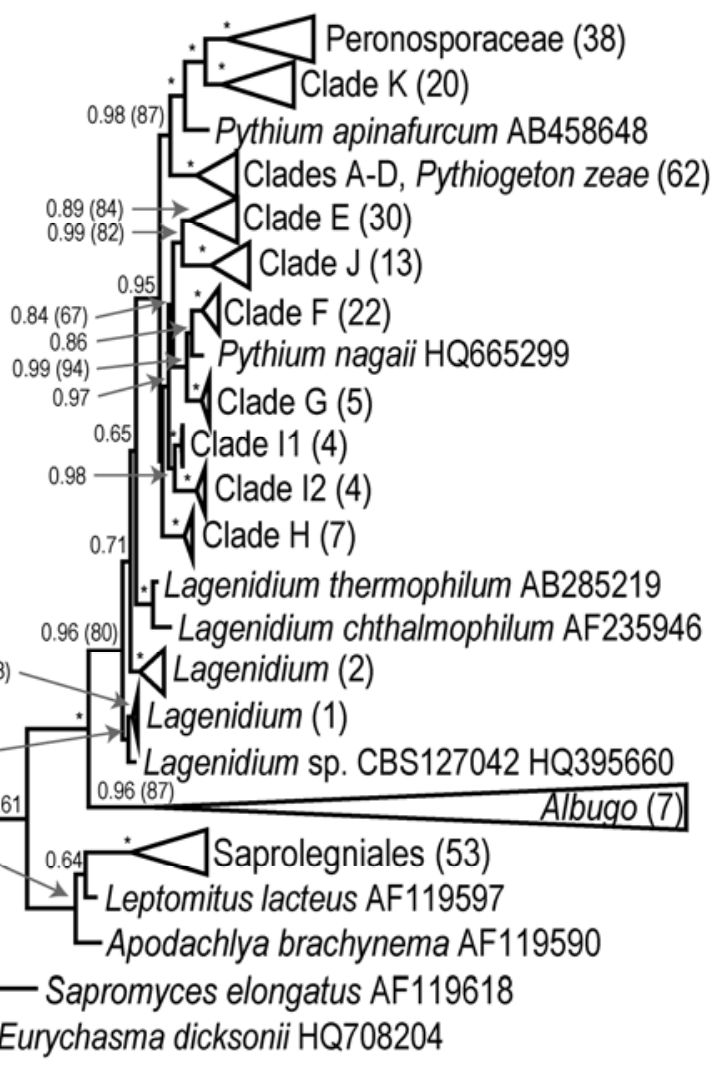

Fig. 5. Phylogeny of Pythium and related oomycetes as inferred from Bayesian analysis of large subunit (LSU) rRNA sequences. This tree represents the consensus between two independent Markov chains run for 34000 cycles (the first 500 cycles were discarded as burn in) under the CATGTR model in PhyloBayes 3.3 (82) with constant characters deleted. Maximum likelihood (ML) analysis was performed in PhyML 3.0 (50) using the best-fit model $(\mathrm{TN} 93+\mathrm{i}+\mathrm{g})$ as estimated in Mega 5.05 (165). ML bootstrap support values were calculated from 100 repeats. Bayesian probability support and $M L$ bootstrap support (in brackets) are indicated when above 0.60 and $60 \%$ respectively. Asterisks (*) indicate support of $>0.95$ and $>95 \%$. Clade titles are followed by numbers in brackets indicating the approximate number of species contained in the clade (some clades contain sequences from undescribed species that were considered synonymous, but might be distinct). The alignment for these analyses consisted of 319 sequences from GenBank $(84,120,136,142,144,170,171,177$, and some unpublished) aligned in MAFFT (66) and manually adjusted in BioEdit 7.0.5.3 (51). 


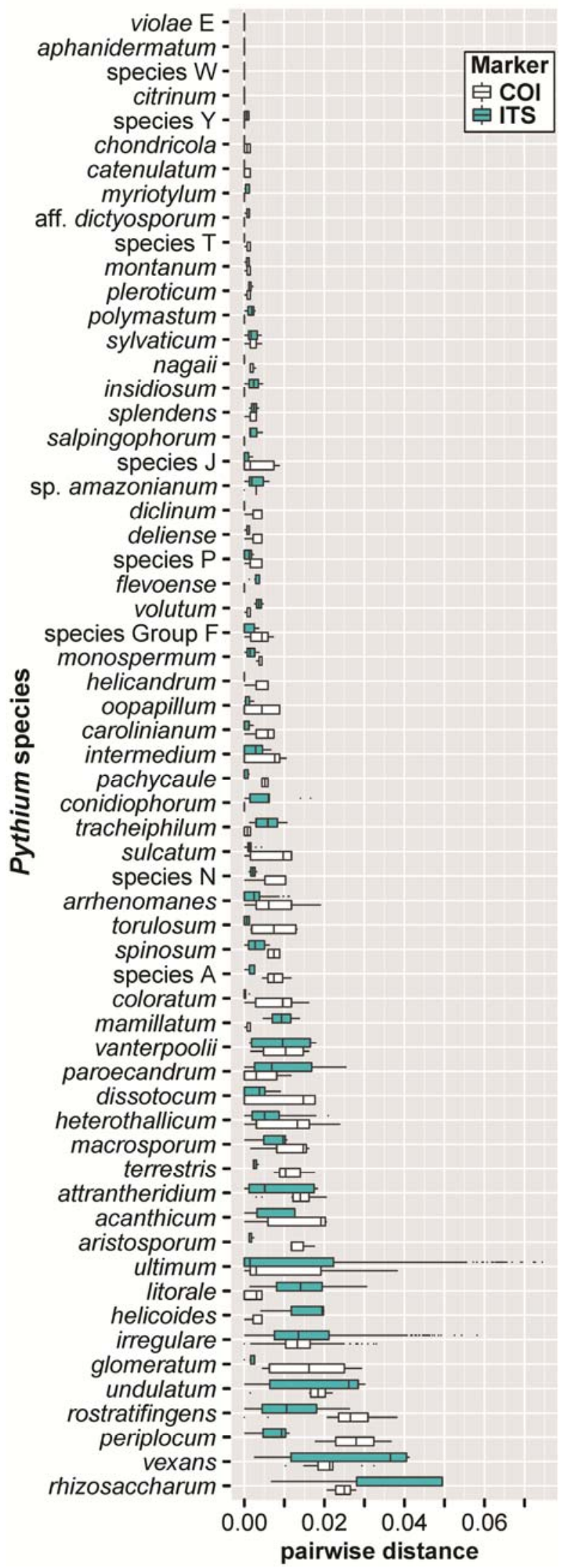

Fig. 6. The ITS and cox1 sequence data of Pythium from Robideau et al. (144) were analyzed with $R(138)$ to generate box plots for all possible pairwise distances within a species. A minimum of three isolates was required to generate a box plot for a species. All cox1 and ITS data are for the same set of strains. The line in the middle of the box is the median, the bottom and the top of the box are the $25^{\text {th }}$ and $75^{\text {th }}$ percentiles and the whiskers are 1.5 times the interquantile range above and below the box limits. The dots are outliers, i.e., beyond \pm 2.7 standard deviations. See Robideau et al. (144) for putative new species in this graph. variation is well characterized in the available reference databases. Sequence polymorphisms with indels are quite common in the ITS for individual isolates of certain species (e.g., Pythium heterothallicum) and can cause a technical issue for sequencing PCR products by Sanger sequencing. At the point of the indel, the sequence will become unreadable since there are two different sequences on top of each other on the electropherogram because synchronicity was lost. If there is only one indel, the reverse sequence will also read until the indel is reached. These partial unidirectional sequences often have enough length and quality to perform an accurate identification. The only way to get the complete sequence of each allele or different copies of the locus in such a case is by cloning before sequencing or by using next generation sequencing technologies.

Almost all Pythium species that are available as live reference strains have been sequenced for at least the ITS and coxl locus, which represents about half of the full species diversity. Attempts should now be made to obtain sequences from the other Pythium species that are only available as specimens. Those species that have never been properly typified, have a poor description, and for which no molecular data can be generated should be formally removed from the accepted list of species.

Species complexes and hybrids. Several Pythium species form part of diverse species complexes that are enshrouded in a fog of taxonomical uncertainty. While the existence of molecular, and in some cases morphological and/or pathogenic, groups within some of these species complexes is undeniable $(44,110,135,150,157)$, it is no simple task to elucidate the species boundaries between or within such groups. Attempts at morphological differentiation within species complexes have been inconclusive due to overlapping characteristics or insignificant differences between putative species in $P$. irregulare $(45,110,156)$ and/or sexual sterility or few morphological representatives in some groups of $P$. vexans (157). On the phylogenetic side, genes commonly used in oomycete taxonomy (ITS, $\operatorname{cox} 1, \operatorname{cox} 2$, and $\beta$-tubulin) can give conflicting or confusing phylogenies at the species complex level and can be used to support or dispute the same new species $(45,157)$. Illdefined species boundaries and invalid or dubious species descriptions preclude reliable species identification of isolates belonging to such complexes and increase the risk of invalid species descriptions. Based on the currently available tools for species identification and description, a conservative approach would seem prudent, especially in new species descriptions. Sequencing of the current barcoding regions (ITS and coxl) should suffice for most species identifications and would at least allow identification of isolates to the species complex level. However, for species descriptions, thorough molecular (and morphological) comparisons of enough strains of putative new taxa and all closely related species would be needed to establish that such taxa are in fact distinct, despite any intra- and interspecific diversity (143). Consequently, both species identification and species description require prior knowledge of the relationships among species. Robideau et al. (144) have provided a good reference standard for this, as well as background on which species are genetically diverse. The 61 Pythium species from Robideau et al. (144) for which there are more than three ITS and coxl sequences were further analyzed for their intraspecific diversity. The species that are known or potential complexes can be seen by their wide range of intraspecific distances (Fig. 6). However, the inability of the ITS, $\operatorname{cox} 1, \operatorname{cox} 2$, and $\beta$-tubulin regions to unambiguously delineate species within some complexes is still problematic, and alternative phylogenetically informative gene regions will have to be identified to solve these taxonomic puzzles. In addition, multispecies coalescent analysis, which can take into account differences among individual gene trees while estimating phylogenetic relationships, will also help clarify relationships among species complexes. Since ITS and coxl do provide a fairly high degree of variation within species complexes, it is likely it will still be possible to identify strains using only these loci once species complexes have been sorted out through an appropriate multigene approach, but this remains to be demonstrated and validated. 
Further complications arise from the potential for some Pythium spp. to form interspecies hybrids. Interspecific hybridization in Pythium has been reported only once; Nechwatal and Mendgen (123) reported a hybrid between Pythium phragmitis and an unknown species close to $P$. phragmitis. As shown in this study, hybridization leads to double peaks in the trace files of nuclear DNA sequences, which complicates identification. Moreover, identification based on mitochondrial DNA, which is maternally inherited, will not accurately identify the hybrid.

\section{Molecular Methods of Identification, Detection, and Quantification}

Serological methods and isozymes. Prior to the widespread use of DNA techniques, serological methods were developed for some Pythium spp. based on antigens in the mycelia and fungal cell walls. Polyclonal antibodies did not have the species-specificity needed for diagnostic purposes, but were useful for controlled studies as a tool to quantify Pythium in roots and study colonization $(80,140)$. An enzyme-linked immunosorbent assay (ELISA) specific to the genus Pythium was developed and used in field studies to look at the early infection of soybean seedlings (121). This technology is useful for situations where the detection of Pythium infestation is important, such as in greenhouses or nurseries, and is marketed as an ELISA kit by Neogen Europe Ltd.-Adgen Phytodiagnostics. Monoclonal antibodies can be much more specific than polyclonal antibodies. A combination of a polyclonal antibody for capture and a monoclonal antibody specific for Pythium ultimum was developed for use in a double-antibody sandwich indirect ELISA $(8,189)$. This assay is highly sensitive, and is marketed as a triple-antibody sandwich indirect ELISA kit by Agdia, Inc. (Elkhart, IN). Advantages of ELISA kits compared to DNA-based methods include their cost, ease of use by growers, sensitivity, and applicability to situations where species identification is not necessary.

While isozymes have been useful for taxonomy and evaluation of species complexes $(11-13,135,167)$, with the development of molecular techniques there are a variety of tools available to facilitate more accurate isolate identification. The choice of techniques to use is dictated by the scientific question being asked as well as the resources available.

RFLP. Comparison of banding profiles of DNA digested with different restriction enzymes can be useful for identification of isolates to a species level; however, the technique is not as accurate as sequence analysis. Digestion of purified mitochondrial DNA (mtDNA) with several restriction enzymes generated banding profiles that were useful for species identification $(58,98,106)$. In view of the amount of work required to purify the mtDNA, this approach is not recommended, although when using restriction enzymes that recognize 4 base pair GC rich cleavage sites, it may be possible to digest total DNA and differentiate the high copy mtDNA from nuclear DNA based on the intensity of specific bands (88). However, depending on the restriction enzymes used, discrete bands may also be seen for rDNA as well. RFLP analysis using cloned sequences as probes in Southern blots has been used for population studies of $P$. ultimum $(41,42)$ and $P$. irregulare $(52,53)$, although techniques described below are more suitable for this purpose.

With the development of PCR and availability of primers capable of amplifying specific regions from a wide range of organisms, techniques were developed for RFLP analysis of PCR-amplified templates. Initial reports evaluated the ability of the nuclear encoded ITS region, small and large rDNA subunits, or the mitochondrially encoded large rDNA subunit to differentiate a range of species (26-28), although subsequent efforts have focused primarily on using the ITS region $(49,62,65,110,139,182)$. This technique has been useful in larger field studies identifying species communities associated with beet disease in Australia (151), carrot cavity spot (160), decline of reed stands (124), and ginseng root diseases (68). In addition to the ITS region, RFLP analysis of portions of the mitochondrially encoded $\operatorname{cox} 2-\operatorname{cox} 1$ gene cluster has been use- ful as well (62); AluI, NlaIII, and RsaI are useful restriction enzymes for this purpose (F. Martin, unpublished). When using any PCR-RFLP analysis, it is important to evaluate phylogenetically related species to ensure the technique can provide the level of species discrimination required.

Single-strand conformational polymorphism (SSCP). Similar to RFLP, SSCP analysis differentiates species based on banding patterns, but rather than generating these by digestion with restriction enzymes, the amplified template is denatured and separated on a nondenaturing gel with the resulting secondary structure of the single-stranded DNA determining the migration rate. Kong et al. (76) described this technique for Pythium using the ITS region as a template and subsequently reported an approach for direct colony amplification, thereby eliminating the need for DNA extraction (75). This approach was effectively used to identify 7,000 isolates collected in a large-scale field program in Ohio (22) and has the advantage that the presence of multiple species in a population study can be modeled (172). This technique also is effective for identification of Phytophthora spp. (74), and a technique for data collection and species identification using an automated DNA sequencer with an internal size standard has been described (Tom Kubisiak, reviewed in 105) and should be useful for Pythium as well.

Species-specific probes. Prior to the development of PCR techniques, one approach that was useful for identification of particular species within a larger sample was Southern analysis with speciesspecific probes. While this often required culturing and extraction of DNA, attempts at using in situ colony lysis on a nylon membrane were evaluated with limited success (F. Martin, unpublished). Lévesque et al. (92) developed a probe from the ITS region specific for $P$. ultimum, while Matthew et al. (111) developed a species-specific probe for identification of $P$. irregulare from a repetitive genomic clone. Klassen et al. (70) developed a more systematic approach for designing species-specific probes. In species with inflated/filamentous sporangia, the 5S rRNA gene is located in the IGS region of the rDNA repeat unit, while for species with spherical/globose sporangia it is dispersed in other regions of the genome as tandem arrays separated by spacer sequences $(15,17)$. Klassen et al. (70) observed that the spacer sequences are divergent enough for designing species-specific probes, which they were able to do for eight different species (there was some cross reactivity between $P$. ultimum var. ultimum and $P$. ultimum var. sporangiiferum). It is likely that the sequences of these spacer regions can also be used for designing species-specific PCR diagnostic assays for species with spherical/globose sporangia.

Portions of the mitochondrial genome are also useful for development of species-specific probes. Regions encompassing length mutations in intraspecific comparisons can be useful for differentiating isolates of the same species, while probes designed from the small unique region of the mitochondrial genome can be useful for species-specific detection (100). A large percentage of the genome is comprised of an inverted repeat that is separated by two single-copy regions referred to as the small and large unique region based on their relative length differences. Comparative genomics of sequenced mitochondrial genomes for a range of species is in progress and should identify additional regions that will be useful for development of species-specific probes (F. Martin, unpublished).

PCR-ELISA for isolate identification. Bailey et al. (9) described a technique using both PCR and ELISA to identify isolates of Pythium to a species level. The ITS region of the extracted DNA was amplified with highly conserved primers in an amplification master mix containing digoxygenin-11-UTP. The amplicon was denatured and added to a streptavidin coated microtiter well containing a biotin labeled capture probe specific for a particular species. The digoxygenin-11-UTP is subsequently detected and quantified immunologically. The availability of a wider range of ITS sequence data (89) and specific oligonucleotide probes used in macroarrays (135) should facilitate broader use of this technique.

Analysis of intraspecific variation and pathogen populations. 
Table 1. Primers used for PCR-based diagnosis and quantification of plant-pathogenic Pythium species

\begin{tabular}{|c|c|c|c|c|c|}
\hline $\begin{array}{l}\text { PCR method } \\
\text { Pathogen species }\end{array}$ & Target host ${ }^{\mathbf{a}}$ & $\begin{array}{l}\text { Target } \\
\text { DNA }^{\mathbf{b}}\end{array}$ & Primers $\left(5^{\prime} \text { to } 3^{\prime}\right)^{\mathrm{c}}$ & Sample type ${ }^{d}$ & Reference \\
\hline \multicolumn{6}{|l|}{ Conventional PCR } \\
\hline P. acanthicum & Not given & ITS & $\begin{array}{l}\text { Pac1 GTGCCTCGTCTTGTTGAAAG } \\
\text { ITS2 GCTGCGTTCTTCATCGATGC }\end{array}$ & Culture & Wang et al. (181) \\
\hline P. aphanidermatum & Not given & ITS & $\begin{array}{l}\text { Pa1 TCCACGTGAACCGTTGAAATC } \\
\text { ITS2 GCTGCGTTCTTCATCGATGC }\end{array}$ & Culture & Wang et al. (181) \\
\hline P. aphanidermatum & Turfgrass & ITS2 & $\begin{array}{l}\text { AsPyF CTGTTCTTTCCTTGAGGTG } \\
\text { AsAPH2B Rev GCGCGTTGTTCACAATAAATTGC }\end{array}$ & Lesion tissue & Asano et al. (6) \\
\hline P. aphanidermatum & $\begin{array}{l}\text { Pea, amaranth, } \\
\text { bok choy, } \\
\text { cucumber }\end{array}$ & $\begin{array}{l}\text { Mt } \\
\text { DNA }\end{array}$ & $\begin{array}{l}\text { P1 GTTCGTTTGTTTGGGGATACG } \\
\text { RP2 CTTCGTACTTAACCAACCAGC }\end{array}$ & $\begin{array}{l}\text { Hydroponic } \\
\text { medium, root } \\
\text { tissue }\end{array}$ & Wang et al. (178) \\
\hline P. arrhenomanes & Not given & ITS & $\begin{array}{l}\text { Par1 AAGTGTAGTTAATTCTGTACGCTGC } \\
\text { ITS2 GCTGCGTTCTTCATCGATGC }\end{array}$ & Culture & Wang et al. (181) \\
\hline P. arrhenomanes & Turfgrass & ITS2 & $\begin{array}{l}\text { AsPyF CTGTTCTTTCCTTGAGGTG } \\
\text { AsARRR CGTCCAAGAGCAATAACCACTC }\end{array}$ & Lesion tissue & Asano et al. (6) \\
\hline P. graminicola & Turfgrass & ITS1 & $\begin{array}{l}\text { AsGRAF GGGCTGCATGTATGTGTAGT } \\
\text { AsPyR ATTCTGCAATTCGCATTAC }\end{array}$ & Lesion tissue & Asano et al. (6) \\
\hline P. helicoides & $\begin{array}{l}\text { Ornamental } \\
\text { flowers, } \\
\text { kalanchoe soil }\end{array}$ & $\mathrm{SCAR}^{\mathrm{e}}$ & $\begin{array}{l}\text { MPhnic 5F CTCGATACGGACGCAAAGGT } \\
\text { MPhnic 5R CATGGCTACAGCTGCTGCAA }\end{array}$ & $\begin{array}{l}\text { Irrigation } \\
\text { water, leaf } \\
\text { tissue }\end{array}$ & Ahonsi et al. (1) \\
\hline P. heterothallicum & Not given & ITS & $\begin{array}{l}\text { Phe1 TTTGTATGAGATCAGCTGAT } \\
\text { ITS2 GCTGCGTTCTTCATCGATGC }\end{array}$ & Culture & Wang et al. (181) \\
\hline P. inflatum & Not given & ITS & $\begin{array}{l}\text { Pinf1 AAGGTGGGCGCATGTATGTG } \\
\text { ITS2 GCTGCGTTCTTCATCGATGC }\end{array}$ & Culture & Wang et al. (181) \\
\hline P. intermedium & Not given & ITS & $\begin{array}{l}\text { Pint } 1 \text { ATACTGCTGGCGGGTGCGAG } \\
\text { ITS2 GCTGCGTTCTTCATCGATGC }\end{array}$ & Culture & Wang et al. (181) \\
\hline P. intermedium & Carrot & ITS & $\begin{array}{l}\text { PINTERf ATGCAGAGGCTGAACGAA } \\
\text { PINTERr CTGTATTCATAGCCGAAACGA }\end{array}$ & $\begin{array}{l}\text { Soil, carrot } \\
\text { tissue }\end{array}$ & Klemsdal et al. (73) \\
\hline P. irregulare & Not given & ITS & $\begin{array}{l}\text { Pir1 AGCGGCGGGTGCTGTTGCAG } \\
\text { ITS2 GCTGCGTTCTTCATCGATGC }\end{array}$ & Culture & Wang et al. (181) \\
\hline P. myriotylum & Ginger & ITS & $\begin{array}{l}\text { Pmy5 GCTGCTGTTATGGCGGACT } \\
\text { ITS2 GCTGCGTTCTTCATCGATGC }\end{array}$ & $\begin{array}{l}\text { Rhizome, buds, } \\
\text { oospores from } \\
\text { soil }\end{array}$ & $\begin{array}{l}\text { Wang et al. (180) } \\
\text { Wang and Chang } \\
\text { (179) }\end{array}$ \\
\hline P. oligandrum & $\begin{array}{l}\text { Button } \\
\text { mushroom }\end{array}$ & ITS & $\begin{array}{l}\text { P.OLIG.F1 CTGTGCTTCGTCGCAAGACT } \\
\text { P.OLIG.R04 CTTTAAAAAGACAGCGCGAGA }\end{array}$ & Compost, soil & Godfrey et al. (48) \\
\hline P. oligandrum & Not given & ITS & $\begin{array}{l}\text { Po1 TGCGTCTATTTTGGATGCGG } \\
\text { ITS2 GCTGCGTTCTTCATCGATGC }\end{array}$ & Culture & Wang et al. (181) \\
\hline P. porphyrae & Seaweed & ITS & $\begin{array}{l}\text { PP-1 TGTGTTCTGTGCTCCTCTCG } \\
\text { PP-2 CCCAAATTGGTGTTGCCTCC }\end{array}$ & Dried seaweed & Park et al. (129) \\
\hline P. porphyrae (nested) & Seaweed & & $\begin{array}{l}\text { OPB-07 GGTGACGCAG, followed by } \\
\text { API TACAAGTCCTGGCCCCTCTCGTGT } \\
\text { APII GAATGCGAGTGGCTCGACGCGTCT }\end{array}$ & $\begin{array}{l}\text { Seafloor } \\
\text { sediment }\end{array}$ & $\begin{array}{l}\text { Kawamura et al. } \\
\text { (67) }\end{array}$ \\
\hline P. rostratum & Not given & ITS & $\begin{array}{l}\text { Pro1 TAGTGTAGCTTTTGTTGCGC } \\
\text { ITS2 GCTGCGTTCTTCATCGATGC }\end{array}$ & Culture & Wang et al. (181) \\
\hline P. splendens & Not given & ITS & $\begin{array}{l}\text { Psp11 GAAGGTCGGAGTAAAATCTGGC } \\
\text { ITS2 GCTGCGTTCTTCATCGATGC }\end{array}$ & Culture & Wang et al. (181) \\
\hline P. spinosum & Not given & ITS & $\begin{array}{l}\text { Pspi1 TGTGTGTTGTGATCGTGCCT } \\
\text { ITS2 GCTGCGTTCTTCATCGATGC }\end{array}$ & Culture & Wang et al. (181) \\
\hline P. sulcatum & Not given & ITS & $\begin{array}{l}\text { Psu3 CACGTGAACCGTAATAATCA } \\
\text { ITS2 GCTGCGTTCTTCATCGATGC }\end{array}$ & Culture & Wang et al. (181) \\
\hline P. sulcatum & Carrot & ITS & $\begin{array}{l}\text { PSULCf GCCGCTTTATTGTGGTCT } \\
\text { PSULCr TCTTCTTTACCCCACAAGTGA }\end{array}$ & $\begin{array}{l}\text { Soil, carrot } \\
\text { tissue }\end{array}$ & Klemsdal et al. (73) \\
\hline P. sylvaticum & Carrot & ITS & $\begin{array}{l}\text { PSYLf CGCTGTGGTTGGTATATTTGT } \\
\text { PSYLr GCCAATTGCACAAGTACAAA }\end{array}$ & $\begin{array}{l}\text { Soil, carrot } \\
\text { tissue }\end{array}$ & Klemsdal et al. (73) \\
\hline P. torulosum & Turfgrass & ITS2 & $\begin{array}{l}\text { AsPyF CTGTTCTTTCCTTGAGGTG } \\
\text { AsTOR6 CGCCTGCCGAAACAGACTAG }\end{array}$ & Lesion tissue & Asano et al. (6) \\
\hline P. ultimum & $\begin{array}{l}\text { Cucumber, } \\
\text { sugar beet, } \\
\text { Chinese } \\
\text { cabbage }\end{array}$ & ITS & $\begin{array}{l}\text { K1 ACGAAGGTTGGTCTGTTG } \\
\text { K3 TCTCTACGCAACTAAATGC }\end{array}$ & $\begin{array}{l}\text { Seedlings, soil, } \\
\text { potato tuber } \\
\text { tissue }\end{array}$ & $\begin{array}{l}\text { Kageyama et al. (63) } \\
\text { Kageyama et al. (61) } \\
\text { El Hadrami et al. (37) }\end{array}$ \\
\hline P. ultimum & Sugar beet & Actin & $\begin{array}{l}\text { 5FWDACT GTATGTGCAAGGCCGGTTT } \\
\text { MIDREVACT ATGAGGCAGACCTAGCCACCAAG }\end{array}$ & $\begin{array}{l}\text { Culture, } \\
\text { seedlings }\end{array}$ & $\begin{array}{l}\text { Weiland and } \\
\text { Sundsbak (185) } \\
\text { ontinued on next page) }\end{array}$ \\
\hline $\begin{array}{l}\text { sp.; bok choy = Brass } \\
\text { subsp. pekinensis; coc } \\
\text { Kalanchoë sp.; pea = } \\
\text { vulgaris subsp. vulgari } \\
\text { b ITS - internal transcrib } \\
\text { c Top, forward primer; b } \\
\text { d Culture - DNA from c } \\
\text { e AFLP - sequence char }\end{array}$ & $\begin{array}{l}\text { turrgrass }=\text { Loysl } \\
\text { spacer of the nu } \\
\text { om, reverse prim } \\
\text { ured isolates. }\end{array}$ & $\begin{array}{l}\text { ia japoni } \\
\text { clear rD } \\
\text { ner. }\end{array}$ & $\begin{array}{l}\text { persica } ; \text { potato }=\text { Solanum } \text { tuberosum; } \text {, seaweed }=\text { Porp } \\
\text { wheat }=\text { Triticum aestivum. } \\
\text {; }- \text { mitochondrial; } \text { rpbl }- \text { ribosomal polymerase B } 1 ; \mathrm{S}\end{array}$ & $\begin{array}{l}\text { ra sp., } P \text {. yezoens } \\
\mathrm{U}-\text { small subunit }\end{array}$ & $\begin{array}{l}\text { zalea }=\text { Rhododendron } \\
\text { bage = Brassica rapa } \\
\text { Vitis sp.; kalanchoe = } \\
\text { isis; sugar beet = Beta } \\
\text { (18S) rDNA. }\end{array}$ \\
\hline
\end{tabular}


Table 1. (continued from preceding page)

\begin{tabular}{|c|c|c|c|c|c|}
\hline $\begin{array}{l}\text { PCR method } \\
\text { Pathogen species }\end{array}$ & Target host ${ }^{\mathbf{a}}$ & $\begin{array}{l}\text { Target } \\
\text { DNA }^{\mathbf{b}}\end{array}$ & Primers $\left(5^{\prime} \text { to } 3^{\prime}\right)^{c}$ & Sample type ${ }^{d}$ & Reference \\
\hline P. ultimum & Potato & ITS & $\begin{array}{l}\text { Pu1F1 GACGAAGGTTGGTCTGTTG } \\
\text { Pu2R1 CAGAAAAAGAAAGGCAAGTTTG }\end{array}$ & $\begin{array}{l}\text { Tuber tissue, } \\
\text { culture }\end{array}$ & Cullen et. al. (31) \\
\hline P. vanterpoolii & Turfgrass & ITS1 & $\begin{array}{l}\text { AsVANF GGTGGATAGCGGCGTATTT } \\
\text { AsPyR ATTCTGCAATTCGCATTAC }\end{array}$ & Lesion tissue & Asano et al. (6) \\
\hline P. violae & Carrot & ITS & $\begin{array}{l}\text { PVIOLf ATGTGTGTGTGCGGGACT } \\
\text { PVIOLr CCACTCCCCAAAGAGAGAAGT }\end{array}$ & $\begin{array}{l}\text { Soil, carrot } \\
\text { tissue }\end{array}$ & Klemsdal et al. (73) \\
\hline P. 'vipa' & Carrot & ITS & $\begin{array}{l}\text { PVIPAf CAGCGGTTGGTATATTCGTT } \\
\text { PVIPAr AAAAAGAAGTGCACAAATAGATGA }\end{array}$ & $\begin{array}{l}\text { Soil, carrot } \\
\text { tissue }\end{array}$ & Klemsdal et al. (73) \\
\hline \multicolumn{6}{|l|}{ Real time PCR } \\
\hline Pythium sp. & $\begin{array}{l}\text { Rotifer } \\
\text { Asplanchna }\end{array}$ & $\begin{array}{l}18 \mathrm{~S} \\
\text { rDNA }\end{array}$ & $\begin{array}{l}\text { Pyth664Fwd GCCCTTTCGGGTGTGTTACTAG } \\
\text { Pyth712Rev CTGAATGGCAGAAGAACATCCTC }\end{array}$ & $\begin{array}{l}\text { Culture, whole } \\
\text { animal }\end{array}$ & Thomas et al. (166) \\
\hline P. abappressorium & Wheat & ITS & $\begin{array}{l}\text { ABA1bF GTTGTTGTGCGTCTGCGGATTTG } \\
\text { ABA1bF GTTGTTGTGCGTCTGCGGATTTG }\end{array}$ & Soil & $\begin{array}{l}\text { Schroeder et al. } \\
(147)\end{array}$ \\
\hline P. attrantheridium & Wheat & ITS & $\begin{array}{l}\text { ATT3F GTTTGTGGTCATTTTGGCTGCG } \\
\text { ATT2R CGCTACTAACAAAGCAGATCCCAG }\end{array}$ & Soil & $\begin{array}{l}\text { Schroeder et al. } \\
(147)\end{array}$ \\
\hline $\begin{array}{l}\text { P. dissotocum } \\
\text { (TaqMan) }\end{array}$ & Tomato & ITS & $\begin{array}{l}\text { up_504 GTTTGGATCGCTTTGCT } \\
\text { lo_702 CCGAAGCTAGAGCGCTT } \\
\text { 183_LNA FAM-TGACTGGAGTTGTTTTCTGTT-BHQ1 }\end{array}$ & Root tissue & $\begin{array}{l}\text { Vallance et al. (172) } \\
\text { Le Floch et al. (83) }\end{array}$ \\
\hline P. heterothallicum & Wheat & ITS & $\begin{array}{l}\text { HET4F GTGAAGTGTCTCGCGCACTTG } \\
\text { HET2R GTAACCATGCATGCTGCACCA }\end{array}$ & Soil & $\begin{array}{l}\text { Schroeder et al. } \\
(147)\end{array}$ \\
\hline P. intermedium & Not given & ITS & $\begin{array}{l}\text { Pf002 GAGTTGCTTTGCTCTCGGC } \\
\text { Pr002b ACACTTCACGTCTGCCACA }\end{array}$ & Forest soil & Li et al. (93) \\
\hline P. irregulare grp I & Wheat & ITS & $\begin{array}{l}\text { IRR3cF GCTGTGGTTGGTGTTTGTTGTTTGC } \\
\text { IRR3R CTGTACAATTGCACACACACAAGTATG }\end{array}$ & Soil & $\begin{array}{l}\text { Schroeder et al. } \\
(147)\end{array}$ \\
\hline $\begin{array}{l}\text { P. irregulare } \\
\text { grps I \& II }\end{array}$ & $\begin{array}{l}\text { American } \\
\text { ginseng }\end{array}$ & ITS & $\begin{array}{l}\text { PiF GTAGCATGCGTGTTTGCTTA } \\
\text { PiR GCAAGCTGTGCATTCATTGC }\end{array}$ & Soil & $\begin{array}{l}\text { Kernaghan et al. } \\
(68)\end{array}$ \\
\hline $\begin{array}{l}P . \text { irregulare } \\
\text { grps I \& II }\end{array}$ & Grapevine & ITS & $\begin{array}{l}\text { PirF1 AGTGTGTGTGGCACGTTGTC } \\
\text { PirR3 GATCAACCCGGAGTATACAAAAC }\end{array}$ & Root tissue & Spies et al. (158) \\
\hline P. irregulare grp IV & Wheat & ITS & $\begin{array}{l}\text { IIV7F GTATCGTCTTGGCGGAGTGG } \\
\text { ABA1R TGCATAAACGAATATACCAACCGC }\end{array}$ & Soil & $\begin{array}{l}\text { Schroeder et al. } \\
(147)\end{array}$ \\
\hline P. oligandrum & Tomato & ITS1 & $\begin{array}{l}\text { HybriOLI-1 GTCTGCGTCTATTTTGGATG } \\
\text { HybriOLI-2 GGATTTGCTGATGTTATTTT }\end{array}$ & Soil & $\begin{array}{l}\text { Takenaka et al. } \\
(163)\end{array}$ \\
\hline $\begin{array}{l}\text { P. oligandrum } \\
\text { (TaqMan) }\end{array}$ & Tomato & ITS & $\begin{array}{l}\text { up_F1 TGCTTCGTCGCAAGACT } \\
\text { lo_146 CGTATTCGGAGTATAGTTCAGT } \\
\text { 142_LNA FAM-AGTCTGCGTCTATTTTGGA-BHQ1 }\end{array}$ & Root tissue & $\begin{array}{l}\text { Vallance et al. (172) } \\
\text { Le Floch et al. (83) }\end{array}$ \\
\hline P. paroecandrum & Wheat & ITS & $\begin{array}{l}\text { PAR2F TGGTTGGCGTTCGTTGTTTG } \\
\text { PAR3R GGATCAACCCGGAGTACACTAATT }\end{array}$ & Soil & $\begin{array}{l}\text { Schroeder et al. } \\
(147)\end{array}$ \\
\hline $\begin{array}{l}\text { P. porphyrae } \\
\text { (Competitive) }\end{array}$ & Seaweed & ITS & $\begin{array}{l}\text { PP-1 TGTGTTCTGTGCTCCTCTCG } \\
\text { PP-2 CCCAAATTGGTGTTGCCTCC } \\
\text { Competitor probe pPPICS }\end{array}$ & $\begin{array}{l}\text { Zoospores in } \\
\text { seawater }\end{array}$ & Park et al. (130) \\
\hline P. rostratifingens & Wheat & ITS & $\begin{array}{l}\text { ROS4F GGTGTAGTCCGGCTTGGAGAAGGA } \\
\text { ROS3R GCGCACCGACAAACGCATACC }\end{array}$ & Soil & $\begin{array}{l}\text { Schroeder et al. } \\
(147)\end{array}$ \\
\hline P. sylvaticum & Wheat & ITS & $\begin{array}{l}\text { SYL1F GTGTCTCGCTGTGGTTGGTATATTTG } \\
\text { SYL2R CTTCTGCCAATTGCACAAGTGC }\end{array}$ & Soil & $\begin{array}{l}\text { Schroeder et al. } \\
(147)\end{array}$ \\
\hline P. ultimum & Tomato & ITS2 & $\begin{array}{l}\text { AFP276 TGTATGGAGACGCTGCATT } \\
\text { ITS4 TCCTCCGCTTATTGATATGC }\end{array}$ & Soil, plant & Lievens et al. (94) \\
\hline P. ultimum (TaqMan) & Potato & ITS & $\begin{array}{l}\text { 92F TGTTTTCATTTTTGGACACTGGA } \\
\text { 166R TCCATCATAACTTGCATTACAACAGA } \\
\text { 116T FAM-CGGGAGTCAGCAGGACGAAGGTTG-VIC }\end{array}$ & $\begin{array}{l}\text { Tuber tissue, } \\
\text { culture }\end{array}$ & Cullen et al. (31) \\
\hline P. ultimum & $\begin{array}{c}\text { American } \\
\text { ginseng }\end{array}$ & ITS & $\begin{array}{l}\text { PuF ATGATGGACTAGCTGATGAA } \\
\text { PuR TTCCATTACACTTCATAGAA }\end{array}$ & Soil & $\begin{array}{l}\text { Kernaghan et al. } \\
(68)\end{array}$ \\
\hline $\begin{array}{l}\text { P. ultimum var. } \\
\text { ultimum }\end{array}$ & Potato & $r p b 1$ & $\begin{array}{l}\text { PultRPB-F GCAGATTGTCCCGGATATTAAC } \\
\text { PultRPB-R CACAATAACCCGAGAATCAAAG }\end{array}$ & Tuber tissue & $\begin{array}{l}\text { Atallah and } \\
\text { Stevenson (7) }\end{array}$ \\
\hline $\begin{array}{l}\text { P. ultimum var. } \\
\text { ultimum }\end{array}$ & Wheat & ITS & $\begin{array}{l}\text { ULT1F GACACTGGAACGGGAGTCAGC } \\
\text { ULT4R AAAGGACTCGACAGATTCTCGATC }\end{array}$ & Soil & $\begin{array}{l}\text { Schroeder et al. } \\
(147)\end{array}$ \\
\hline $\begin{array}{l}\text { P. ultimum var. } \\
\text { ultimum (TaqMan) }\end{array}$ & Grapevine & ITS & $\begin{array}{l}\text { PulF2 GCAGGACGAAGGTTGGTCTG } \\
\text { PulR2 GTCCCCACAGTATAAATCAGTATTTAGGT } \\
\text { PulP2 VIC-TGGACTAGCTGATGAACTT-MGB }\end{array}$ & Root tissue & Spies et al. (158) \\
\hline $\begin{array}{l}\text { P. ultimum var. } \\
\text { ultimum }\end{array}$ & Peach & SSU & $\begin{array}{l}\text { SplendF5 TGTAGGTTTGAGACTTC } \\
\text { SplendR5 CTATCGATCAAGGTTGTAT }\end{array}$ & Root tissue & Bent et al. (18) \\
\hline$P$. vexans & Peach & SSU & $\begin{array}{l}\text { VexansF2 TATACAACCTTGATCGAC } \\
\text { VexansR2 GATGGAAAATTGCAACC }\end{array}$ & Root tissue & Bent et al. (18) \\
\hline P. vexans (TaqMan) & Grapevine & ITS & $\begin{array}{l}\text { PvF1 TTTCCGTTTTGTGCTTGATG } \\
\text { PvR1 AGCGAACACACCCAATAAGC } \\
\text { VexP1 HEX }{ }^{\mathrm{TM}} \text {-CCGTGTCTGCTGGCGGGTC-Iowa } \\
\text { Black }^{\circledR} \text { FQ }\end{array}$ & Root tissue & Spies et al. (158) \\
\hline
\end{tabular}


Techniques such as random amplified polymorphic DNAs (RAPDs) and amplified fragment length polymorphism (AFLP) analysis have been used for analysis of intraspecific variation and population studies. Both techniques have the advantage that genomic sequence information from the species under investigation is not needed to generate the markers; however, these markers are not codominant, which is important when working with a diploid organism. Also, RAPDs may not be reproducible among labs, but cloning and designing a new amplification primer pair to generate SCAR markers (sequence characterized amplified regions) can alleviate this problem (1). RAPDs have been used to evaluate intraspecific variation of $P$. ultimum $(65,167), P$. irregulare (110), P. porphyrae (131), P. spinosum (46), and P. insidiosum (128), the species community in Egypt (47), Pythium species community analysis of carrot cavity spot (32), species recovered from chili (122), and population studies with P. ultimum $(41,42)$. AFLP analyses have been used to investigate species boundaries in the $P$. irregulare complex (44) as well as population structure of $P$. aphanidermatum, $P$. irregulare, and $P$. ultimum $(43,85), P$. aphanidermatum and $P$. spinosum in Oman $(2,3)$, and differentiate isolates of $P$. myriotylum virulent on cocoyam (135).

Due to their codominance, a better technique for population studies in Pythium is simple sequence repeats (SSR) analysis, also referred to as microsatellites. This technique does require knowledge of the genomic sequences for designing the appropriate primers for amplification of target regions but can provide a robust dataset for population analysis. Lee and Moorman (86) designed SSR primers for $P$. aphanidermatum, $P$. irregulare, and $P$. cryptoirregulare. While SSR primers are generally not transferable across species, some amplification of phylogenetically related species was observed with these primers. For example, all primers for $P$. irregulare also amplified $P$. cryptoirregulare, and some amplified $P$. sylvaticum, $P$. intermedium, $P$. cylindrosporum, and $P$. spinosum. Likewise, some primers for $P$. aphanidermatum also amplified $P$. graminicola, $P$. dissotocum, $P$. myriotylum, and $P$. torulosum. Surprisingly, five of the primers also amplified templates from most of the 22 Pythium spp. evaluated, although it was not confirmed by sequence analysis if SSRs were present in these amplicons. The $P$. aphanidermatum primers were subsequently used in conjunction with AFLP analysis to evaluate the population structure of the pathogen in Pennsylvania greenhouse nurseries (85). Primers for SSR analysis have also been developed for $P$. insidiosum (162) and Phytopythium helicoides (96). With the recent sequencing of the P. ultimum nuclear genome (89) and several other species in progress, the availability of data for primer design should increase the utility of SSR analysis.

It is possible to use SSRs in the genome for differentiation of isolates without knowing genomic sequences for primer design. Inter-simple sequence repeat (ISSR) analysis uses a single primer designed from concatenation of a SSR sequence (for example, $[\mathrm{GACA}]_{4}$ ), and when these sequences are in close proximity in a genome in opposite orientation, a band can be amplified. Vasseur et al. (175) used this approach for differentiating isolates in Pythium group F (filamentous sporangia), and Vallance et al. (172) used it to differentiate isolates of $P$. oligandrum.

Array based detection. One technique that can be very useful for identifying all species that may be present in a given sample is the use of arrays (also referred to as reverse dot blot). Highly conserved primers are used to amplify a template from extracted DNA spanning the region used to design the hybridization probes that are fixed onto a nylon membrane. During amplification, the DNA is labeled and then used as a probe in Southern analysis with the array. Advantages of this technique are the ability to include hybridization probes specific for a range of species on the array, thereby giving a larger community analysis of the sample; the use of hybridization probes designed from multiple loci, thereby providing confirmation of the resulting identification; the ability to include positive controls to ensure the technique is working properly as well as having clade-specific hybridization probes to detect any yet-to-be-identified species that may be present; and the ability to quantify the target species based on the intensity of the hybridization signal.

Lévesque et al. $(91,92)$ observed that a macroarray using the ITS1 region as a hybridization probe could be effective for identification of Pythium spp., but it lacked the species specificity necessary for evaluation of environmental samples. Using species-specific oligonucleotides improved this specificity, and accurate detection of $P$. acanthicum, $P$. aphanidermatum, and $P$. ultimum (both $P$. ultimum var. ultimum and var. sporangiiferum hybridized) was observed (91). A microarray was also developed for $P$. ultimum by Lievens et al. (95). Tambong et al. (164) developed a macroarray using the ITS region of the rDNA for designing species-specific oligonucleotide hybridization probes less than $25 \mathrm{bp}$ in length. More than 100 species were identified by the 172 oligonucleotides. Le Floch et al. (83) used this array for investigating the colonization of tomato roots by $P$. oligandrum and used the intensity of the hybridization signal to quantify the extent of colonization. The array also allowed for the identification of $P$. dissotocum and several other species in the experimental system. Izzo and Mazzola (59) designed a similar array for detection of a range of fungi in their analysis of fungal communities, including Pythium spp., but used the entire ITS 1 and 2 region as the target sequence. The array was not widely tested for specificity of detection of Pythium spp., but with the six species evaluated specificity at the level of phylogenetic grouping was observed (for example, $P$. sylvaticum also hybridized to the $P$. irregulare probe). Overall species specificity was observed if sequence divergence was greater than 5 to $10 \%$. Working with $P$. aphanidermatum, as well as several Eumycotan fungi, Njambere et al. (125) observed improved sensitivity and reduced variability of the hybridization signal with their ITS array when the hybridization oligonucleotide probes were present as dimers. While some cross hybridization was observed, this generally occurred when the mismatched bases were present toward the end of the probe, and it was suggested that redesign to move the polymorphic base more toward the middle of the oligonucleotide would alleviate this problem.

PCR-based detection and quantification. Limitations imposed by conventional diagnoses provided the impetus to exploit PCRbased methods for the identification and detection of Pythium species. Conventional (endpoint) PCR, commercially available since the mid-1980s, has been used for specific identification of at least 23 plant-pathogenic Pythium species from diverse agricultural systems (Table 1). In most cases, researchers sought to identify cultured isolates or to detect known species in soils or infected plant tissues. The ITS region has been widely used for primer design, although other DNA sequences have been informative and specific $(18,181,185)$. Multiplexing of assays was possible if the primers hybridized specifically to the target DNA, and the size difference of the PCR amplicons could be distinguished using gel electrophoresis (6). Quantification of target DNA was possible by titrating the amplification of the target DNA with known amounts of a competitor having near-sequence identity to the target amplicon but distinguishable from it, e.g., by harboring a unique endonuclease cleavage site. Removal of the competitor by endonuclease treatment prior to gel electrophoresis allowed visualization of the target amplicon; as the molar amount of competitor exceeded that of the target, the intensity of staining of the target DNA band approached background. This method was used to quantify $P$. porphyrae, a pathogen of the seaweed used in sushi (130).

Fluorescence detection technology, integrated into PCR platforms in the 1990s, made possible the monitoring of product amplification after each PCR cycle, in real time. The amount of target DNA present in a sample is inversely proportional to the fractional cycle number $\left(C_{t}\right)$ at which the amplicon is first detected (its fluorescence exceeds baseline or background fluorescence). Using real-time, or quantitative, PCR technology, researchers could eliminate gel electrophoresis as a method of product validation, and instead use melting temperature as an amplicon-specific characteristic. Additional advantages of real-time technology include sensitivity over 5 to $7 \log$ concentration units of target and 
high sample throughput (up to 384 samples per run). Real-time PCR has been used to quantify 14 plant-pathogenic Pythium species (Table 1). In eight real-time PCR reports, researchers made use of SYBR Green, in which this fluorescent dye binds to doublestranded DNA during each of the annealing and extension steps. In three reports, an alternative fluorescence chemistry, called TaqMan, makes use of forward and reverse PCR primers and a fluorescently labeled probe (127). The advantage of the TaqMan chemistry is its ability to distinguish a single nucleotide polymorphism within the probe binding site, conferring a higher degree of target specificity as well as the ability to multiplex amplifications.

Copy number of marker and quantification. The officially approved coxl barcode and the proposed ITS barcode are present in multiple copies in the genome. This can be a significant advantage when trying to amplify DNA from difficult templates and for direct detection of species from environmental samples. While the copy number of the ITS locus has not been determined for Pythium, there is indirect evidence to suggest there may be variation in copy numbers at an intra- as well as interspecific level (104). The results presented by Spies et al. (158) also suggest this is the case for $P$. vexans. Standard curves for a $\mathrm{qPCR}$ assay based on the ITS region were different depending on the phylogenetic subgrouping of the species that was used. The estimates of DNA concentration based on $\mathrm{C}_{\mathrm{t}}$ differed by more than two orders of magnitude among the $P$. vexans subgroupings. With a similar ITS assay for $P$. ultimum and $P$. irregulare, the intraspecific variability was generally less than one order of magnitude (158). This indicates that it is important to keep the possibility of multiple gene copies in mind when developing assays (array or PCR based) that will be used to quantify the presence of a pathogen and do the appropriate tests to determine if this will influence the accuracy of the results obtained. In a soil quantification assay for Verticillium dahliae, Bilodeau et al. (19) estimated copy number differences in the IGS rDNA for a geographically diverse collection of isolates ranging from 24 to 73 copies per genome. This resulted in a difference in $\mathrm{C}_{t}$ of approximately 1.8 among isolates when the results were normalized relative to amplification of single-copy genes to account for differences in DNA concentration or purity among extracted DNA. This type of experimental approach should be used when trying to evaluate relative copy numbers of a multiple copy target. However, this did not appear to have an effect on the accuracy of results obtained from soil quantification assays when results were compared to traditional soil plating assays $\left(R^{2}=0.96\right)$. While mitochondrial loci are also present in high copy number relative to nuclear loci, it is uncertain if their copy number varies during different phases of the pathogen's life cycle and if this would influence the accuracy of quantification assays; this needs to be evaluated experimentally. In addition, since mitochondria are maternally inherited (97), their utility for investigating population genetics may be limited to clonally reproducing or strictly selfing species.

Environmental samples. Both conventional and real-time PCR are adaptable to evaluating many types of environmental samples, including soils, irrigation water, and hydroponic samples, well as natural and artificially infected host tissues (Table 1). Constraints to amplification include efficiency of extraction of Pythium DNA from the sample, the purity of extracted DNA, distribution of the pathogen in the sample, host tissue type, and possibly the state (age) of the infected tissue. The form or developmental stage of the pathogen does not appear to be a factor in DNA extraction, as DNA from zoospores isolated from soil and seawater has been recovered $(132,179)$, and pressure cycling technology for DNA extraction from natural and infested soils containing Pythium spp. did not result in higher quantities of pathogen DNA (K. L. Schroeder and P. A. Okubara, unpublished data). Pressure cycling DNA extraction has been effective in pathogen DNA recovery from host tissue that is refractory to homogenization, such as lyophilized roots (126). Real-time PCR quantification is subject to interference by fluorescent molecules present in agricultural samples, especially in soils with high organic (humic and fulvic acid) content, or in infected tissues that have accumulated fluor- escent secondary metabolites. One way to ameliorate this problem is the addition of polyvinylpolypyrrolidone to the extracted DNA. Compounds that covalently bind DNA and interfere with the amplification process are also problematic in PCR (20). Because of the potential problem of PCR inhibitors and other potential experimental errors inherent with PCR assays, the use of internal standards and controls to evaluate amplification efficiency is necessary when performing quantification assays $(19,54)$.

Examples of quantification using real-time PCR-detection systems. A major challenge to studying Pythium spp. in situ is the wide diversity of species often found within a soil (133) or a given infected tissue (158). Pythium spp. may also be co-infecting with plant-pathogenic fungi, complicating the determination of the importance of each causal agent $(7,31)$. In addition, like many soilborne pathogens such as Rhizoctonia, Pythium is not uniformly distributed in soil, making quantification more difficult. Traditional plating methods together with microscopic identification of species have proven useful in teasing these interactions apart and collecting isolates. However, real-time PCR has made it possible to not only identify each species, but to quantify the populations of these organisms, and in many cases with greater sensitivity than traditional methods. The utilization of real-time PCR for quantification of Pythium has been applied in a wide range of studies. It has been used to quantify species of Pythium in soil $(68,93,147)$, quantifying pathogen DNA in mixed infections with other genera of organisms $(7,18,31,94)$, monitoring biological control isolates of $P$. oligandrum $(83,163,172)$, and quantifying Pythium DNA in rotifers (166).

Schroeder et al. (147) developed species-specific primers for nine species of pathogenic Pythium commonly found in Washington soils. When used in combination with SYBR Green real-time PCR, each species could be reliably and specifically amplified and subsequently quantified. Using DNA extracted from cultures, quantification was possible down to $10 \mathrm{fg}$ of pathogen DNA per reaction. In this study, quantification of 1 to 5 propagules per gram of $P$. irregulare group I, $P$. irregulare group IV, and $P$. ultimum var. ultimum was possible. When used in a survey (148), as many as nine species could be found in a single location. Using traditional plating techniques, Paulitz and Adams (133) found only six species per soil. In addition to species frequency, use of realtime PCR also allows for quantification of DNA for each species, giving information of species prevalence within a given sample. The use of real-time PCR in following Pythium species diversity in eastern Washington soils has shed light on the geographic distribution of these different species (147) and even suggested host preferences for certain species of Pythium in the dryland cropping system of eastern Washington (K. L. Schroeder and T. C. Paulitz, unpublished). Likewise, Kernaghan et al. (68) used a SYBR Green assay based on ITS sequences for quantification of $P$. ultimum and $P$. irregulare in ginseng soil, while $\mathrm{Li}$ et al. (93) developed a similar type of ITS assay for quantification of $P$. intermedium in forest soils from Japan. Li et al. (93) observed a good correlation between the results of real-time PCR and population densities assayed from naturally infested soils $\left(R^{2}=\right.$ $0.97)$ down to an inoculum density of 12 colony-forming units/g soil.

In addition to examining populations of pathogenic species of Pythium, real-time PCR has also been used to quantify nonpathogenic isolates of Pythium oligandrum being used for biological control $(83,163,172)$. These authors used two different strategies to monitor increases in DNA, including the TaqMan assay and hybridization probes. After introduction of $P$. oligandrum, quantities of this organism could be detected in plant roots during the 6-month duration of study using real-time PCR (TaqMan), while traditional plating techniques were not useful for monitoring the reduced populations beyond 3 months (83). In fact, the quantity of $P$. oligandrum DNA detected in the later months of the experiment was found to increase above the lowest level detected in the fourth month of the experiment, yet dilution plating did not show the presence of $P$. oligandrum in the roots. Le Floch 
et al. (83) point out that this is likely due to competition on the growth medium with other Pythium spp., a disadvantage of using traditional methods to assess the species composition and populations in a sample. Populations of the pathogenic P. dissotocum were also monitored using real-time PCR, DNA array hybridization, and dilution plating (83). Similar results were obtained with each assay, although the real-time PCR appeared to be slightly more sensitive, detecting low quantities of $P$. dissotocum DNA in the first month of the experiment that were not detected by DNA array hybridization. The real-time PCR results for both $P$. oligandrum and $P$. dissotocum were positively correlated with the results from DNA array hybridization $\left(R^{2}=0.63\right.$ and 0.89 , respectively; both at $P<0.0001$ ), a technique that was also used for validation of the real-time PCR assay developed by Schroeder et al. (147). A similar approach was developed by Takenaka et al. (163) to monitor P. oligandrum as a biological control for Ralstonia solanacearum on tomato. However, they developed a realtime PCR assay employing hybridization probes in which two probes are used and fluorescence is detected following transfer of energy from a donor fluor on the first probe to an acceptor fluor on the second. When added to nonsterilized and sterilized soils, $P$. oligandrum DNA was quantifiable by real-time PCR 3 weeks after inoculation when the initial inoculum density exceeded $5 \times 10^{5}$ oospores per plant. However, a low quantity of DNA was also detected in the sterilized soils when $5 \times 10^{4}$ oospores were added and the assay detected a background population of $P$. oligandrum already present in the nonsterilized soil ( 9 pg DNA/g dry soil).

The versatility of this technique is exemplified by its continued application to new situations. Recently, real-time PCR was employed to quantify the presence of Pythium as a parasite in an animal system (166). This group developed a quantitative PCR assay using SYBR Green I to examine the relationship between diseased rotifers and the presence of a potentially novel Pythium sp. as the causal agent. The Pythium sp. of interest could not be cultured outside the host, but by comparing the copy number of the 18S rRNA gene in Pythium with the proportion of infected individuals within different rotifer populations, the authors were able to strongly correlate $\left(R^{2}=0.96\right)$ the presence of the Pythium sp. with infected individuals. This information was used to support the concept that the Pythium sp. was indeed the causal agent.

Quality control guidelines for quantitative real-time PCR have been developed by Bustin et al. (25). These guidelines outline the Minimum Information for publication of Quantitative real-time PCR Experiments (MIQE).

\section{Future Directions}

Describing new species and changes in the code. There were several Pythium species described after the monograph of Van der Plaats-Niterink (173) that will have to be synonymized. Lévesque and de Cock (90) highlighted several species that need to be further investigated for this, but there have been additional questionable species described since. There are close to 300 published Pythium species names available, but only $50 \%$ of these are commonly used and applied to live strains. Dried holotypes are degraded and not taxonomically useful in some cases, and illustrations serving as types are often ambiguous. The authors of most names, if not all, of the recently described species did not perform a review of the old literature to demonstrate that their new species had not been described before under a different name. Therefore, even if a species appears to be distinct when compared only against the species for which there are molecular data, the new species name could be synonymized if somebody shows that it is similar to an obscure species described a long time ago that would have priority. The 18th International Botanical Congress of 2011 will be seen as a historical moment in mycology. The name of the "International Code of Botanical Nomenclature" was changed to the "International Code of Nomenclature for algae, fungi, and plants", with the lowercase word fungi including oomycetes (114). As of 1 January 2012, a Latin description is no longer required as long as there is one in English, and an electronic publication in ISSN or ISBN numbered publications with PDF formatting for new species or higher taxa names is now acceptable. This will potentially increase the publication of new Pythium species since it will remove some significant hurdles. The above changes are for the entire botanical community, but there were additional proposals brought forward by the mycological community to that meeting that were approved (55) and that will have a major impact in mycology and plant pathology (187). As of 1 January 2013, all new species names of fungi will have to get an identifier obtained by an approved repository of names, for which MycoBank is the leading candidate. The other major change for the mycological community is the complete overhaul of article 59 that allowed a dual naming system for teleomorphic and anamorphic states of the same species. The unambiguous linkage of these lifecycle stages through molecular phylogenetics made this article redundant. This has no direct impact for the oomycete research or extension community since the dual name system was never used to separate asexual and sexual stages; however, we could, and the authors of this article believe that we should, use the provisions of the new articles 14 and 56. The changes to these articles relate to conservation or rejection of names primarily to make a transition to "one fungus = one name" more controlled. Existing committees such as The Committee for Fusarium Taxonomy could be mandated to develop lists of accepted specific and generic names for approval by the Nomenclatural Committee for Fungi of the International Botanical Congress. Whereas several committees are being organized to do that for various other groups of true Fungi, an oomycete subcommission under the International Commission on the Taxonomy of Fungi (ICTF) could be created to perform this task. Via a combination of a list of rejected names, with or without type designations, and another list of preferred names with types over other typified names, a list of accepted names could be created. If these lists included all known species names, it would no longer be necessary to re-evaluate old obscure names or to worry about overturning accepted species names.

As previously noted, the future descriptions of new species should preferably include multiple isolates (from geographically diverse areas if possible) with morphological characterizations to provide insight into intraspecific variation in these features. At a minimum, ITS and coxl sequence data should be collected and compared to the Barcode Of Life Database (BOLD) dataset to ensure uniqueness, with sequencing of additional loci (e.g., $\beta$-tubulin) to resolve any ambiguity. With the current effort in a number of labs to generate additional sequence data for phylogenetic analysis of the genus, it is anticipated that additional loci should be available for this purpose in the not too distant future.

Should Pythium be kept as a single genus? It is now well accepted that members of higher taxonomic groups, e.g., a genus, should be monophyletic, in that such a group should comprise all the descendants of a common ancestor. Currently, these are hypothetical and unknown for the different genera of oomycetes. With the inclusion of $P$. vexans and its associated species from clade $\mathrm{K}$, it has been well established that Pythium represents a polyphyletic grouping. The species belonging to clade $\mathrm{K}$ are truly intermediate between Pythium and Phytophthora both morphologically and phylogenetically. The genus Phytopythium was proposed for clade $\mathrm{K}$ at the Third International Phytophthora, Pythium and related genera Workshop in Torino in 2008 (see www.phytophthoradb.org/pdf/O8LevesquePM.pdf), and a type species for Phytopythium Abad et al. was published as a hard copy in the spring of 2010 (10). Another name for this clade was proposed and published as a hard copy in the fall of 2010 (170). However, Ovatisporangium is an invalid name because it does include the type of the genus Phytopythium which was published before Ovatisporangium was proposed. With genomes being now available for both Pythium and Phytophthora species, it will be interesting to see if the genomes of Phytopythium spp. are Phytophthora-like, Pythium-like, or in between.

Making major taxonomic changes such as splitting an economically important genus like Pythium should be done with 
great caution. In the long term, splitting the genus along monophyletic genealogical lines is desirable on a practical level since important biological characteristics are most likely to be correlated with such clades. If the molecular phylogenies used to make these separations are robust, the new taxonomy is likely to be stable and maintained over time. It is probable that additional changes will be needed in Pythium, but we should make sure that any change becomes stable. In the absence of a very high degree of support for a proposed change, the conservative and appropriate approach is to keep the status quo. Robustness of a phylogeny depends primarily on the selection of markers, the sampling of taxa, and the proper analysis of the data. In order to generate meaningful phylogenies to make decisions about whether or not to split Pythium, it will be essential to include genera closely related to Pythium such as Lagenidium, Myzocytiopsis, or Pythiogeton to make sure they are not embedded within Pythium. Most phylogenetic studies of oomycetes that include Pythium use only one or two of the most common phylogenetic markers such as SSU, LSU, and cox2 and have a low or only a partial sampling of Pythium species $(14,81,170)$. As demonstrated by our phylogenetic analyses with SSU and LSU with broad sampling of Pythium, the support for many clades was very low. Kuramae et al. (78) showed that in Fungi it is possible to find robust phylogenetic markers through a phylogenomics approach. With the increasing number of oomycete genomes available, we believe that such an approach should be undertaken to find phylogenetic markers that would provide solid and consistent support for the oomycete and Pythium clades. Once such analyses are completed with broad sampling within Pythium and related genera, it will be possible to evaluate if the genus needs to be split further.

Review of old names. Before making decisions to split Pythium, it will be necessary to verify if any former genera have their type within any of the monophyletic clades. The genus Pythium Pringsheim was described in 1858, with P. monospermum as the type. This species, which has filamentous, noninflated sporangia, is a member of clade A. In subsequent years, many species with other types of sporangia have been assigned to Pythium, and other genus names have been proposed for species that can be associated with Pythium. Attempts to split Pythium into genera or subgenera have been made in the past, however, these divisions were not generally accepted.

The first genus associated with Pythium was Artotrogus described by Montagane (117). For unknown reasons this genus, which has priority above Pythium, was not accepted. Much later, Van der Plaats-Niterink submitted a proposal to reject the name (174). However, the type species of Artotrogus is A. hydnosporus (=Pythium hydnosporum), which is a member of clade D. If this clade is to be separated from Pythium, the old name may have to be resurrected. Roze and Cornu (145) described Cytosiphon, type C. pythioides (=Pythium pythioides). This is the first valid generic name for Pythium species with globose sporangia. However, the oospores have a reticulate thick wall, which is unknown in other Pythium species. The identity cannot be confirmed due to a lack of material, and it cannot be unambiguously assigned to one of the clades with globose sporangia. Fischer (39) proposed a subdivision of Pythium into three subgenera: Pythium subgenus Aphragmium for species with filamentous sporangia, not delimited by a septum from subtending hyphae; Pythium subgenus Nematosporangium for species with filamentous sporangia, delimited by a septum; and Pythium subgenus Sphaerosporangium for species with globose sporangia. One year later, Schröter (149) proposed to elevate Nematosporangium (also including Aphragmium) to the genus level; however, this name is illegitimate because it comprises the type species of Pythium. In 1915, Edson (36) published the genus Rheosporangium Edson, based on the type species $R$. aphanidermatum (=Pythium aphanidermatum); however, since this species belongs to clade A (which also contains the Pythium-type species $P$. monospermum), the name Rheosporangium is a later synonym of Pythium. Sparrow (154) noted that Fischer's subgenus Aphragmium does not make sense since it is unlikely that a spo- rangium is not delimited by a septum. He proposed to elevate the subgenus Sphaerosporangium to the genus level, leaving the species with filamentous sporangia in Pythium sensu stricto. Uzuhashi et al. (170) broke up the genus into five genera. Pythium Pringsheim emend. Uzuhashi, Tojo \& Kakishima comprises the species with filamentous sporangia (clades A, B, C, and D [90]). The new genus Ovatisporangium comprises clade $\mathrm{K}$ and is a synonym for the previously published Phytopythium, as pointed out above. Globisporangium comprises the species with globose sporangia, clades E, F, G, I, and J (90) and is likely a synonym of the previously published Sphaerosporangium. Elongisporangium comprises the species with elongated clavate sporangia (clade $\mathrm{H}$ [90]), although it does share a common ancestor with the species with globose sporangia based on SSU and LSU phylogeny (Figs. 4 and 5). Pilasporangium was erected for the species P. apinafurcum. For other subdivisions of Pythium in groups or sections and subsections, see Van der Plaats-Niterink $(173,174)$.

Splitting the genus Pythium will have a significant impact for the community of plant pathologists. Robust phylogenetic analysis with better markers and more complete sampling of Pythium species with species from the genera Pythiogeton Minden, Lagenidium Schenk, Myzocytium Schenk, Myzocytiopsis Dick, and Chlamydomyzium Dick should be produced and considered before old names are reintroduced or new names are accepted by the community.

Novel detection technologies. While current technology has supported the development of accurate and sensitive molecular diagnostic techniques, these often require DNA purification, the availability of more expensive and sophisticated equipment, and more highly trained technical personnel to run the assay. The development of techniques that could reduce the need for DNA purification and could be run by less highly trained personnel on less expensive equipment would broaden the use of molecular diagnostics. While trials have not been conducted with Pythium spp., there are several promising technologies that might address these needs. Tomlinson et al. (168) reported on a technique for detection of Phytophthora ramorum that used the nitrocellulose test strip from an immunological detection technique as a source for the DNA (no DNA extraction was done) and an isothermal LAMP amplification for detection. Another isothermal amplification technique called nicking enzyme amplification reaction (NEAR) is also under development for detection of bacterial pathogens and is reported to be less sensitive to contaminants in the extracted DNA (155).

Julich et al. (60) developed a technique where a single assay unit was used for all aspects of analysis. This "lab on a chip" has the advantage that everything to run the assay was self-contained, only the sample DNA needed to be added. Rather than fluorescence, electrical conductivity was measured and the assay run could be completed in as little as $10 \mathrm{~min}$. While the ITS-2 assays designed for $P$. oligandrum and $P$. ultimum did not generate a signal above the threshold, the ones for five Phytophthora species did; since the threshold values were determined by assaying closely related species for background, improving the specificity of the hybridization probes for the Pythium spp. should address this problem.

The ability to examine the community structure of Pythium spp. within an ecosystem would improve our understanding of the ecological niche that specific species occupy and the influence of environment on their survival. Techniques such as PCR-RFLP $(68,124,160), \operatorname{SSCP}(23,172)$, and macroarrays $(59,91,92,95,164)$ have been successfully used for this purpose, but there are limitations with sample throughput and identification of unknown or new species when investigating large replicated trials. With the improvement in DNA sequencing technology, reduction in cost, and improvement in computational support for managing large datasets, an alternative approach is to use highly conserved primers to amplify a specific region that exhibits enough sequence divergence to allow species identification. The resulting amplicons are cloned and sequenced with BLAST analysis used to provide a species name for each sequence. This approach was used by Arcate et al. (5) for evaluation of Peronosporomycete rhizosphere com- 
munities, using both an Oomycete and Saprolegniomycetidae based primer pair designed from the 28S rDNA. With the Oomycete primer pair, Pythium was the most common genus recovered, and while most species could be identified by BLAST analysis, some were unique, suggesting the full diversity of this genus is yet to be fully appreciated. These primers have also been used to evaluate Oomycete communities in apple rhizosphere $(146,159,188)$, while Bent et al. (18) reported another primer pair designed from the small rDNA subunit that was specific for stramenopiles. Kwaśna et al. (79) used a similar approach for evaluating fungal community on wheat roots. The ITS region was amplified using highly conserved primers and cloned; RFLP analysis was used to differentiate groups of clones with sequencing of a much smaller subset of clones used to identify species. With next-generation sequencing technologies (such as pyrosequencing and perhaps Illumina or Pacific Biosciences), it is possible to directly sequence the amplicons without the need for cloning, an approach that was used by Sugiyama et al. (161) in their analysis of microbial communities in organic and conventional potato farms using the ITS 1 region. Although primers with the ability to amplify template from a wide range of microorganisms was used, $P$. ultimum was detected in this system. Development of Peronosporomycetespecific primers from a locus that did not vary in copy number across species would facilitate the effective use of this approach for evaluating the diversity of species as well as their relative abundance in an ecosystem.

\section{Acknowledgments}

We thank Scott Redhead for his dedication in maintaining nomenclatural stability and for extremely useful discussions on how the new changes in the code could become an opportunity for oomycete taxonomy. We thank the Washington Grain Commission for support of research on detection and quantification of Pythium spp.

\section{Literature Cited}

1. Ahonsi, M. O., Ling, Y., and Kageyama, K. 2010. Development of SCAR markers and PCR assays for single or simultaneous species-specific detection of Phytophthora nicotianae and Pythium helicoides in ebb-andflow irrigated kalanchoe. J. Microbiol. Methods 83:260-265.

2. Al-Sa'di, A. M., Drenth, A., Deadman, M. L., and Aitken, E. A. B. 2008. Genetic diversity, aggressiveness and metalaxyl sensitivity of Pythium aphanidermatum populations infecting cucumber in Oman. Plant Pathol. 57:45-56.

3. Al-Sa'di, A. M., Drenth, A., Deadman, M. L., De Cock, A. W. A. M., AlSaid, F. A., and Aitken, E. A. B. 2008. Genetic diversity, aggressiveness and metalaxyl sensitivity of Pythium spinosum infecting cucumber in Oman. J. Phytopathol. 156:29-35.

4. Alexopoulos, C. J., Mims, C. W., and Blackwell, M. 1996. Introductory Mycology. Wiley and Sons, New York.

5. Arcate, J. M., Karp, M. A., and Nelson, E. B. 2006. Diversity of Peronosporomycete (oomycete) communities associated with the rhizosphere of different plant species. Microbiol. Ecol. 51:36-50.

6. Asano, T., Senda, M., Suga, H., and Kageyama, K. 2010. Development of multiplex PCR to detect five Pythium species related to turfgrass diseases. J. Phytopathol. 158:609-615.

7. Atallah, Z. K., and Stevenson, W. R. 2006. A methodology to detect and quantify five pathogens causing potato tuber decay using real-time quantitative polymerase chain reaction. Phytopathology 96:1037-1045.

8. Avila, F. J., Yuen, G. Y., and Klopfenstein, N. B. 1995. Characterization of a Pythium ultimum-specific antigen and factors that affect its detection using a monoclonal antibody. Phytopathology 85:1378-1387.

9. Bailey, A. M., Mitchell, D. J., Manjunath, K. L., Nolasco, G., and Niblett, C. L. 2002. Identification to the species level of the plant pathogens Phytophthora and Pythium by using unique sequences of the ITS1 region of ribosomal DNA as capture probes for PCR ELISA. FEMS Microbiol. Lett. 207:153-158.

10. Bala, K., Robideau, G. P., Lévesque, C. A., de Cock, A. W. A. M., Abad, Z. G., Lodhi, A. M., Shahsad, S., Ghaffar, A., and Coffey, M. D. 2010. Phytopythium Abad et al. gen. nov. and Phytopythium sindhum Lodhi et al. sp. nov. Fungal Planet 49. Persoonia 24:136-137.

11. Barr, D. J. S., Warwick, S. I., and Desaulners, N. L. 1996. Isozyme variation, morphology, and growth response to temperature in Pythium ultimum. Can. J. Bot. 74:753-761.

12. Barr, D. J. S., Warwick, S. I., and Desaulners, N. L. 1997. Isozyme variation in heterothallic species and related asexual isolates of Pythium. Can. J. Bot. 75:1927-1935.

13. Barr, D. J. S., Warwick, S. I., and Desaulners, N. L. 1997. Isozyme variation, morphology, and growth response to temperature in Pythium irregulare. Can. J. Bot. 75:2073-2081.

14. Beakes, G. W., and Sekimoto, S. 2009. The evolutionary phylogeny of oomycetes - insights gained from studies of holocarpic parasites of algae and invertebrates. Pages 1-24 in: Oomycete Genetics and Genomics. K. Lamour and S. Kamoun, eds. John Wiley \& Sons, New York.

15. Bedard, J. E. J., Schurko, A. M., Cock, A. W. A. M., and Klassen, G. R. 2006. Diversity and evolution of 5S rRNA gene family organization in Pythium. Mycol. Res. 110:86-95.

16. Belbahri, L., McLeod, A., Paul, B., Calmin, G., Moralejo, E., Spies, C. F. J., Botha, W. J., Clemente, A., Descals, E., Sanchez-Hernandez, E., and Lefort, F. 2008. Intraspecific and within-isolate sequence variation in the ITS rRNA gene region of Pythium mercuriale sp. nov. (Pythiaceae). FEMS Microbiol. Lett. 284:17-27.

17. Belkhiri, A., Buchko, J., and Klassen, G. R. 1992. The 5S ribosomal RNA gene in Pythium species: Two different genomic locations. Mol. Biol. Evol. 9:1089-1102.

18. Bent, E., Loffredo, A., Yang, J. I., McKenry, M. V., Becker, J. O., and Borneman, J. 2009. Investigations into peach seedling stunting caused by a replant soil. FEMS Microbiol. Ecol. 68:192-200.

19. Bilodeau, G. J., Koike, S. T., Uribe, P., and Martin, F. N. 2011. Development of an assay for rapid detection and quantification of Verticillium dahliae in soil. Phytopathology 102:331-343.

20. Braid, M. D., Daniels, L. M., and Kitts, C. L. 2003. Removal of PCR inhibitors from soil by chemical flocculation. J. Microbiol. Methods 52:389-393.

21. Briard, M., Dutertre, M., Rouxel, F., and Brygoo, Y. 1995. Ribosomal RNA sequence divergence within the Pythiaceae. Mycol. Res. 99:11191127.

22. Broders, K. D., Lipps, P. E., Paul, P. A., and Dorrance, A. E. 2007. Characterization of Pythium spp. associated with corn and soybean seed and seedling disease in Ohio. Plant Dis. 91:727-735.

23. Broders, K. D., Wallhead, M., Paul, P. A., Lipps, P. E., and Dorrance, A. E. 2008. Assessing Pythium population dynamics from different soil regions in Ohio. (Abstr.) Phytopathology 98:S26.

24. Buchko, J., and Klassen, G. R. 1990. Detection of length heterogeneity in the ribosomal DNA of Pythium ultimum by PCR amplification of the intergenic region. Curr. Genet. 18:203-205.

25. Bustin, S. A., Benes, V., Garson, J. A., Hellmans, J., Huggett, J., Kubista, M., Mueller, R., Nolan, T., Pfaffl, M. W., Shipley, G. L., Vandesompele, J., and Wittwer, C. T. 2009. The MIQE guidelines: Minimum Information for publication of Quantitative real-time PCR Experiments. Clin. Chem 55:611-622.

26. Chen, W. 1992. Restriction fragment length polymorphisms in enzymatically amplified ribosomal DNAs of three heterothallic Pythium species. Phytopathology 82:1467-1472.

27. Chen, W., and Hoy, J. W. 1993. Molecular and morphological comparison of Pythium arrhenomanes and P. graminicola. Mycol. Res. 97:1371-1378.

28. Chen, W., Hoy, J. W., and Schneider, R. W. 1992. Species-specific polymorphism in transcribed ribosomal DNA of five Pythium species. Exp. Mycol. 16:22-34.

29. Cook, R. J., and Veseth, R. J. 1991. Wheat Health Management. American Phytopathological Society, St. Paul, MN.

30. Cooke, D. E. L., Drenth, A., Duncan, J. M., Wagels, G., and Brasier, C. M. 2000. A molecular phylogeny of Phytophthora and related oomycetes. Fungal Genet. Biol. 30:17-32.

31. Cullen, D. W., Toth, I. K., Boonham, N., Walsh, K., Barker, I., and Lees, A. K. 2007. Development and validation of conventional and quantitative polymerase chain reaction assays for the detection of storage rot potato pathogens, Phytophthora erythroseptica, Pythium ultimum and Phoma foveata. J. Phytopathol. 155:309-315.

32. Davison, E. M., MacNish, G. C., Murphy, P. A., and McKay, A. G. 2003. Pythium spp. from cavity spot and other root diseases of Australian carrots. Australas. Plant Pathol. 32:455-464.

33. Dick, M. W. 1990. Key to Pythium. University of Reading Press, Reading, UK.

34. Dick, M. W., Vick, M. C., Gibbings, J. G., Hedderson, T. A., and LopezLastra, C. C. 1999. 18S rDNA for species of Leptolegnia and other Peronosporomycetes: Justification for the subclass taxa Saprolegniomycetidae and Peronosporomycetidae and division of the Saprolegniaceae sensu lato into the Leptolegniaceae and Saprolegniaceae. Mycol. Res. 103:1119-1125.

35. Dobler, S., and Müller, J. K. 2000. Resolving phylogeny at the family level by mitochondrial cytochrome oxidase sequences: Phylogeny of carrion beetles (Coleoptera, Silphidae). Mol. Phylogen. Evol. 15:390-402.

36. Edson, H. A. 1915. Rheosporangium aphanidermatum, a new genus and species of fungus parasitic on sugar beets and radishes. J. Agric. Res. 4:279-292.

37. El Hadrami, A., Wally, O., Adam, L. R., and Daayf, F. 2007. PCR-based determination of colonization patterns during potato tuber infection by single and multiple pathogens. Eur. J. Plant Pathol. 117:201-218. 
38. Farr, D. F., and Rossman, A. Y. 2012. Fungal Nomenclature Database, Systematic Mycology and Microbiology Laboratory, ARS, USDA. http://nt.ars-grin.gov/fungaldatabases/fungushost/FungusHost.cfm.

39. Fischer, A. 1892. Phycomycetes. Rabenhorst, Kryptogamenflora 1:505.

40. Förster, H., Coffey, M. D., Elwood, H., and Sogin, M. L. 1990. Sequence analysis of the small subunit ribosomal RNAs of three zoosporic fungi and implications for fungal evolution. Mycologia 82:306-312.

41. Francis, D. M., Gehlen, M. F., and St. Clair, D. A. 1994. Genetic variation in homothallic and hyphal swelling isolates of Pythium ultimum var. ultimum and $P$. ultimum var. sporangiferum. Mol. Plant-Microbe Interact. 7:766-775.

42. Francis, D. M., and St-Clair, D. A. 1993. Outcrossing in the homothallic oomycete, Pythium ultimum, detected with molecular markers. Curr. Genet. 1993. 24:100-106.

43. Garzon, C. D., Geiser, D. M., and Moorman, G. W. 2005. Diagnosis and population analysis of Pythium species using AFLP fingerprinting. Plant Dis. 89:81-89.

44. Garzón, C. D., Geiser, D. M., and Moorman, G. W. 2005. Amplified fragment length polymorphism analysis and internal transcribed spacer and coxII sequences reveal a species boundary within Pythium irregulare. Phytopathology 95:1489-1498.

45. Garzón, C. D., Yánez, J. M., and Moorman, G. W. 2007. Pythium cryptoirregulare, a new species within the $P$. irregulare complex. Mycologia 99:291-301.

46. Gherbawy, Y. A. M. H., and Abdelzaher, H. M. A. 2002. Using of RAPDPCR for separation of Pythium spinosum Sawada into two varieties: var. spinosum and var. sporangiiferum. Cytologia 67:83-94.

47. Gherbawy, Y. A. M. H., Abdelzaher, H. M. A., Meens, J., and El-Hariry, H. 2005. Morphological and molecular identification of some closely related Pythium species in Egypt. Arch. Phytopathol. Plant Prot. 38:193-208.

48. Godfrey, S. A. C., Monds, R. D., Lash, D. T., and Marshall, J. W. 2003. Identification of Pythium oligandrum using species-specific ITS rDNA PCR oligonucleotides. Mycol. Res. 107:790-796.

49. Gómez-Alpízar, L., Saalau, E., Picado, I., Tambong, J. T., and Saborío, F. 2011. A PCR-RFLP assay for identification and detection of Pythium myriotylum, causal agent of the cocoyam root rot disease. Lett. Appl. Microbiol. 52:185-192.

50. Guindon, S., Dufayard, J.-F., Lefort, V., Anisimova, M., Hordijk, W., and Gascuel, O. 2010. New algorithms and methods to estimate maximumlikelihood phylogenies: Assessing the performance of PhyML 3.0. Syst. Biol. 59:307-321.

51. Hall, T. A. 1999. BioEdit: A user-friendly biological sequence alignment editor and analysis program for Windows 95/98/NT. Nucleic Acids Sympos. Ser. 41:95-98.

52. Harvey, P. R., Butterworth, P. J., Hawke, B. G., and Pankhurst, C. E. 2000. Genetic variation among populations of Pythium irregulare in southern Australia. Plant Pathol. 49:619-627.

53. Harvey, P. R., Butterworth, P. J., Hawke, B. G., and Pankhurst, C. E. 2001. Genetic and pathogenic variation among cereal, medic and sub-clover isolates of Pythium irregulare. Mycol. Res. 105:85-93.

54. Haudenshield, J. S., and Hartman, G. L. 2011. Exogenous controls increase negative call veracity in multiplexed, quantitative PCR assays for Phakopsora pachyrhizi. Plant Dis. 95:343-352.

55. Hawksworth, D. L. 2012. Managing and coping with names of pleomorphic fungi in a period of transition. Mycosphere 3:52-64.

56. Hering, T. F., Cook, R. J., and Tang, W. H. 1987. Infection of wheat embryos by Pythium species during seed germination and the influence of seed age and soil matric potential. Phytopathology 77:1104-1108.

57. Hong, C. X., and Moorman, G. W. 2005. Plant pathogens in irrigation water: Challenges and opportunities. Crit. Rev. Plant Sci. 24:189-208.

58. Huang, H. C., Morrison, R. J., Muendel, H. H., Barr, D. J. S., Klassen, G. R., and Buchko, J. 1992. Pythium sp. "group G", a form of Pythium ultimum causing damping-off of safflower. Can. J. Plant Pathol. 14:229-232.

59. Izzo, A. D., and Mazzola, M. 2009. Hybridization of an ITS-based macroarray with ITS community probes for characterization of complex communities of fungi and fungal-like protists. Mycol. Res. 113:802-812.

60. Julich, S., Riedel, M., Kielpinski, M., Urban, M., Kretschmer, R., Wagner, S., Fritzsche, W., Henkel, T., Möller, R., and Werres, S. 2011. Development of a lab-on-a-chip device for diagnosis of plant pathogens. Biosensors Bioelectron. 26:4070-4075.

61. Kageyama, K., Komatsu, T., and Suga, H. 2003. Refined PCR protocol for detection of plant pathogens in soil. J. Gen. Plant Pathol. 69:153-160.

62. Kageyama, K., Nakashima, A., Kajihara, Y., Suga, H., and Nelson, E. B. 2005. Phylogenetic and morphological analyses of Pythium graminicola and related species. J. Gen. Plant Pathol. 71:174-182.

63. Kageyama, K., Ohyama, A., and Hyakumachi, M. 1997. Detection of Pythium ultimum using polymerase chain reaction with species-specific primers. Plant Dis. 81:1155-1160.

64. Kageyama, K., Senda, M., Asano, T., Suga, H., and Ishiguro, K. 2007. Intra-isolate heterogeneity of the ITS region of rDNA in Pythium helicoides. Mycol. Res. 111:416-423.

65. Kageyama, K., Uchino, H., and Hyakumachi, M. 1998. Characterization of the hyphal swelling group of Pythium: DNA polymorphisms and cultural and morphological characteristics. Plant Dis. 82:218-222.
66. Katoh, K., Kuma, K.-i., Toh, H., and Miyata, T. 2005. MAFFT version 5 Improvement in accuracy of multiple sequence alignment. Nucleic Acids Res. 33:511-518.

67. Kawamura, Y., Yokoo, K., Tojo, M., and Hishiike, M. 2005. Distribution of Pythium porphyrae, the causal agent of red rot disease of Porphyrae spp., in the Ariake Sea, Japan. Plant Dis. 89:1041-1047.

68. Kernaghan, G., Reeleder, R. D., and Hoke, S. M. T. 2008. Quantification of Pythium populations in ginseng soils by culture dependent and real-time PCR methods. Appl. Soil Ecol. 40:447-455.

69. Kirk, P. M., Cannon, P. F., Minter, D. W., and Stalpers, J. A. 2008 Ainsworth \& Bisby's Dictionary of the Fungi, 10th ed. CAB International, Wallingford, UK.

70. Klassen, G., Balcerzak, M., and de Cock, A. W. A. M. 1996. 5S ribosomal RNA gene spacers as species-specific probes for eight species of Pythium. Phytopathology 86:581-587.

71. Klassen, G. R., and Buchko, J. 1990. Subrepeat structure of the intergenic region in the ribosomal DNA of the oomycetous fungus Pythium ultimum. Curr. Genet. 17:125-127.

72. Klassen, G. R., McNabb, S. A., and Dick, M. W. 1987. Comparison of physical maps of ribosomal DNA repeating units in Pythium, Phytophthora and Apodachlya. J. Gen. Microbiol. 133:2953-2959.

73. Klemsdal, S. S., Herrero, M. L., Wanner, L. A., Lund, G., and Hermansen, A. 2008. PCR-based identification of Pythium spp. causing cavity spot in carrots and sensitive detection in soil samples. Plant Pathol. (Oxford) 57:877-886

74. Kong, P., Hong, C., Richardson, P. A., and Gallegly, M. E. 2003. Singlestrand-conformational polymorphisms of ribosomal DNA for rapid species differentiation in genus Phytophthora. Fungal Genet. Biol. 39:238-249.

75. Kong, P., Richardson, P. A., and Hong, C. 2005. Direct colony PCR-SSCP for detection of multiple pythiaceous oomycetes in environmental samples. J. Microbiol. Methods 61:25-32.

76. Kong, P., Richardson, P. A., Moorman, G. W., and Hong, C. X. 2004. A molecular fingerprint for identification of multiple Pythium species. (Abstr.) Phytopathology 94:S55.

77. Küpper, F. C., Maier, I., Müller, D. G., Loiseaux-De Goer, S., and Guillou, L. 2006. Phylogenetic affinities of two eukaryotic pathogens of marine macroalgae, Eurychasma dicksonii (Wright) Magnus and Chytridium polysiphoniae Cohn. Cryptogamie, Algologie 27:165-184.

78. Kuramae, E., Robert, V., Echavarri-Erasun, C., and Boekhout, T. 2007. Cophenetic correlation analysis as a strategy to select phylogenetically informative proteins: An example from the fungal kingdom. BMC Evol. Biol. 7:134.

79. Kwaśna, H., Bateman, G. L., and Ward, E. 2010. Microbiota in wheat roots evaluated by cloning of ITS1/2 rDNA and sequencing. J. Phytopathol. 158:278-287.

80. Kyuchukova, M. A., Büttner, C., Gabler, J., Bar-Yosef, B., Grosch, R., and Kläring, H. P. 2006. Evaluation of a method for quantification of Pythium aphanidermatum in cucumber roots at different temperatures and inoculum densities. J. Plant Dis. Prot. 113:113-119.

81. Lara, E., and Belbahri, L. 2011. SSU rRNA reveals major trends in oomycete evolution. Fungal Divers. 49:93-100.

82. Lartillot, N., Lepage, T., and Blanquart, S. 2009. PhyloBayes 3: A Bayesian software package for phylogenetic reconstruction and molecular dating. Bioinformatics 25:2286-2288.

83. Le Floch, G., Tambong, J., Vallance, J., Tirilly, Y., Lévesque, A., and Rey, P. 2007. Rhizosphere persistence of three Pythium oligandrum strains in tomato soilless culture assessed by DNA macroarray and real-time PCR. FEMS Microbiol. Ecol. 61:317-326.

84. Leclerc, M. C., Guillot, J., and Deville, M. 2000. Taxonomic and phylogenetic analysis of Saprolegniaceae (Oomycetes) inferred from LSU rDNA and ITS sequence comparisons. Antonie Van Leeuwenhoek 77:369 377.

85. Lee, S., Garzón, C. D., and Moorman, G. W. 2010. Genetic structure and distribution of Pythium aphanidermatum populations in Pennsylvania greenhouses based on analysis of AFLP and SSR markers. Mycologia 102:774-784.

86. Lee, S., and Moorman, G. W. 2008. Identification and characterization of simple sequence repeat markers for Pythium aphanidermatum, P. cryptoirregulare, and $P$. irregulare and the potential use in Pythium population genetics. Curr. Genet. 53:81-93.

87. Lévesque, C. A. 2011. Fifty years of oomycetes-from consolidation to evolutionary and genomic exploration. Fungal Divers. 50:35-46.

88. Lévesque, C. A., Beckenbach, K., Baillie, D. L., and Rahe, J. E. 1993. Pathogenicity and DNA restriction fragment length polymorphisms of isolates of Pythium spp. from glyphosate-treated seedlings. Mycol. Res. 97:307-312.

89. Lévesque, C. A., Brouwer, H., Cano, L., Hamilton, J. P., Holt, C., Huitema E., Raffaele, S., Robideau, G. P., Thines, M., Win, J., Zerillo, M. M., Beakes, G. W., Boore, J. L., Busam, D., Dumas, B., Ferriera, S., Fuerstenberg, S. I., Gachon, C. M. M., Gaulin, E., Govers, F., GrenvilleBriggs, L., Horner, N., Hostetler, J., Jiang, R. H. Y., Johnson, J., Krajaejun, T., Lin, H., Meijer, H. J. G., Moore, B., Morris, P., Phuntmart, V., Puiu, D., Shetty, J., Stajich, J. E., Tripathy, S., Wawra, S., van West, P., Whitty, B. R., Coutinho, P. M., Henrissat, B., Martin, F., Thomas, P. D., Tyler, B. M. 
De Vries, R. P., Kamoun, S., Yandell, M., Tisserat, N., and Buell, C. R. 2010. Genome sequence of the necrotrophic plant pathogen Pythium ultimum reveals original pathogenicity mechanisms and effector repertoire. Genome Biology 11.

90. Lévesque, C. A., and de Cock, A. W. A. M. 2004. Molecular phylogeny and taxonomy of the genus Pythium. Mycol. Res. 108:1363-1383.

91. Lévesque, C. A., Harlton, C. E., and Cock, A. W. A. M. 1998. Identification of some oomycetes by reverse dot blot hybridization. Phytopathology 88:213-222.

92. Lévesque, C. A., Vrain, T. C., and De Boer, S. H. 1994. Development of a species-specific probe for Pythium ultimum using amplified ribosomal DNA. Phytopathology 84:474-478.

93. Li, M., Senda, M., Komatsu, T., Suga, H., and Kageyama, K. 2010. Development of real-time PCR technique for the estimation of population density of Pythium intermedium in forest soils. Microbiol. Res. 165:695705 .

94. Lievens, B., Brouwer, M., Vanachter, A. C. R. C., Cammue, B. P. A., and Thomma, B. P. H. J. 2006. Real-time PCR for detection and quantification of fungal and oomycete tomato pathogens in plant and soil samples. Plant Sci. 171:155-165.

95. Lievens, B., Brouwer, M., Vanachter, A. C. R. C., Lévesque, C. A., Cammue, B. P. A., and Thomma, B. P. H. J. 2005. Quantitative assessment of phytopathogenic fungi in various substrates using a DNA macroarray. Environ. Microbiol. 7:1698-1710.

96. Ling, Y., Zhou, W., Motohashi, K., Suga, H., Fukui, H., and Kageyama, K. 2009. Development of microsatellite markers for Pythium helicoides. FEMS Microbiol. Lett. 293:85-91.

97. Martin, F. N. 1989. Maternal inheritance of mitochondrial DNA in sexual crosses of Pythium sylvaticum. Curr. Genet. 16:375-376.

98. Martin, F. N. 1990. Taxonomic classification of asexual isolates of Pythium ultimum based on cultural characteristics and mitochondrial DNA restriction patterns. Exp. Mycol. 14:47-56.

99. Martin, F. N. 1990. Variation in the ribosomal DNA repeat unit within single-oospore isolates of the genus Pythium. Genome 33:585-591.

100. Martin, F. N. 1991. Selection of DNA probes useful for isolate identification of two Pythium spp. Phytopathology 81:742-746.

101. Martin, F. N. 1992. Pythium. Pages 39-49 in: Methods for Research on Soilborne Phytopathogenic Fungi. L. L. Singleton, J. D. Mihail, and C. M. Rush, eds. American Phytopathological Society, St. Paul, MN.

102. Martin, F. N. 1995. Meiotic instability of Pythium sylvaticum as demonstrated by inheritance of nuclear markers and karyotype analysis. Genetics 139:1233-1246.

103. Martin, F. N. 2000. Phylogenetic relationships among some Pythium species inferred from sequence analysis of the mitochondrially encoded cytochrome oxidase II gene. Mycologia 92:711-727.

104. Martin, F. N. 2009. Pythium Genetics. Pages 213-239 in: Oomycete Genetics and Genomics. K. Lamour and S. Kamoun, ed. John Wiley and Sons, Hoboken, NJ.

105. Martin, F. N., Coffey, M. D., Zeller, K., Hamelin, R. C., Tooley, P., Garbelotto, M., Hughes, K. J. D., Kubisiak, T., Bilodeau, G. J., Levy, L., Blomquist, C., and Berger, P. H. 2009. Evaluation of molecular markers for Phytophthora ramorum detection and identification; testing for specificity using a standardized library of isolates. Phytopathology 99:390-403.

106. Martin, F. N., and Kistler, H. C. 1990. Species-specific banding patterns of restriction endonuclease-digested mitochondrial DNA from the genus Pythium. Exp. Mycol. 14:32-46.

107. Martin, F. N., and Loper, J. E. 1999. Soilborne plant diseases caused by Pythium spp.: Ecology, epidemiology, and prospects for biological control. Crit. Rev. Plant Sci. 18:111-181.

108. Martin, F. N., and Tooley, P. W. 2003. Phylogenetic relationships among Phytophthora species inferred from sequence analysis of mitochondrially encoded cytochrome oxidase I and II genes. Mycologia 95:269-284.

109. Matsumoto, C., Kageyama, K., Suga, H., and Hyakumachi, M. 1999. Phylogenetic relationships of Pythium species based on ITS and 5.8S sequences of the ribosomal DNA. Mycoscience 40:321-331.

110. Matsumoto, C., Kageyama, K., Suga, H., and Hyakumachi, M. 2000. Intraspecific DNA polymorphisms of Pythium irregulare. Mycol. Res. 104:1333-1341.

111. Matthew, J., Hawke, B. G., and Pankhurst, C. E. 1995. A DNA probe for identification of Pythium irregulare in soil. Mycol. Res. 99:579-584.

112. Matthews, V. D. 1931. Studies on the Genus Pythium. University of North Carolina Press, Chapel Hill.

113. Mazzola, M. 1998. Elucidation of the microbial complex having a causal role in the development of apple replant disease in Washington. Phytopathology 88:930-938.

114. McNeill, J., Turland, N. J., Monro, A. M., and Lepschi, B. J. 2011. XVIII International Botanical Congress: Preliminary mail vote and report of Congress action on nomenclature proposals. Taxon September:14 pp.

115. Middleton, J. T. 1943. The taxonomy, host range, and geographic distribution of the genus Pythium. Mem. Torrey Bot. Club 20:1-171.

116. Miura, M., Hatai, K., Tojo, M., Wada, S., Kobayashi, S., and Okazaki, T. 2010. Visceral mycosis in Ayu Plecoglossus altivelis larvae caused by Pythium flevoense. Fish Pathol. 45:24-30.

117. Montagane, C. 1845. Editorial. Gardner's Chronicle 38:640.
118. Moralejo, E., Clemente, A., Descals, E., Belbahri, L., Calmin, G., Lefort, F., Spies, C. F. J., and McLeod, A. 2008. Pythium recalcitrans sp. nov. revealed by multigene phylogenetic analysis. Mycologia 100:310-319.

119. Morita, Y., and Tojo, M. 2007. Modifications of PARP medium using fluazinam, miconazole, and nystatin for detection of Pythium spp. in soil. Plant Dis. 91:1591-1599.

120. Muraosa, Y., Morimoto, K., Sano, A., Nishimura, K., and Hatai, K. 2009. A new peronosporomycete, Halioticida noduliformans; gen. et sp. nov., isolated from white nodules in the abalone; Haliotis; spp. from Japan. Mycoscience 50:106-115.

121. Murillo-Williams, A., and Pedersen, P. 2008. Early incidence of soybean seedling pathogens in Iowa. Agron. J. 100:1481-1487.

122. Muthukumar, A., Eswaran, A., Mathiyazhagan, S., and Kumar, S. 2010 Morphological and molecular characterisation of Pythium species causing chilli (Capsicum annuum L.) damping-off. Arch. Phytopathol. Plant Prot. 43:1543-1550.

123. Nechwatal, J., and Mendgen, K. 2009. Evidence for the occurrence of natural hybridization in reed-associated Pythium species. Plant Pathol. 58:261-270.

124. Nechwatal, J., Wielgoss, A., and Mendgen, K. 2008. Diversity, host, and habitat specificity of oomycete communities in declining reed stands (Phragmites australis) of a large freshwater lake. Mycol. Res. 112:689696.

125. Njambere, E. N., Clarke, B. B., and Zhang, N. 2011. Dimeric oligonucleotide probes enhance diagnostic macroarray performance. J. Microbiol. Methods 86:52-61.

126. Okubara, P. A., Li, C., Schroeder, K. L., Schumacher, R. T., and Lawrence, N. P. 2007. Improved extraction of Rhizoctonia and Pythium DNA from wheat roots and soil samples using pressure cycling technology. Can. J. Plant Pathol. 29:304-310.

127. Okubara, P. A., Schroeder, K. L., and Paulitz, T. C. 2005. Real-time polymerase chain reaction: Applications to studies on soilborne pathogens. Can. J. Plant Pathol. 27:300-313.

128. Pannanusorn, S., Chaiprasert, A., Prariyachatigul, C., Krajaejun, T., Vanittanakom, N., Chindamporn, A., Wanachiwanawin, W., and Satapatayavong, B. 2007. Random amplified polymorphic DNA typing and phylogeny of Pythium insidiosum clinical isolates in Thailand. Southeast Asian J. Trop. Med. Publ. Health 38:383-391.

129. Park, C. 2006. Rapid detection of Pythium porphyrae in commercial samples of dried Porphyra yezoensis sheets by polymerase chain reaction. J. Appl. Phycol. 18:203-207.

130. Park, C., Kakinuma, M., and Amano, H. 2001. Detection and quantitative analysis of zoospores of Pythium porphyrae, causative organism of red rot disease in Porphyra, by competitive PCR. J. Appl. Phycol. 13:433-441.

131. Park, C., Kakinuma, M., Sakaguchi, K., and Amano, H. 2003. Genetic variation detected with random amplified polymorphic DNA markers among isolates of the red rot disease fungus Pythium porphyrae isolated from Porphyra yezoensis from Korea and Japan. Fish. Sci. 69:361368 .

132. Park, C. S., Kakinuma, M., and Amano, H. 2001. Detection of the red rot disease fungi Pythium spp. by polymerase chain reaction. Fish. Sci. 67:197-199.

133. Paulitz, T. C., and Adams, K. 2003. Composition and distribution of Pythium communities in wheat fields in eastern Washington state. Phytopathology 93:867-873.

134. Paulitz, T. C., and Baker, R. 1988. The formation of secondary sporangia by Pythium ultimum: The influence of organic amendments and Pythium nunn. Soil Biol. Biochem. 20:151-156.

135. Perneel, M., Tambong, J. T., Adiobo, A., Floren, C., Saborio, F., Lévesque, A., and Hofte, M. 2006. Intraspecific variability of Pythium myriotylum isolated from cocoyam and other host crops. Mycol. Res. 110:583-593.

136. Petersen, A. B., and Rosendahl, S. 2000. Phylogeny of the Peronosporomycetes (Oomycota) based on partial sequences of the large ribosomal subunit (LSU rDNA). Mycol. Res. 104:1295-1303.

137. Phillips, A. J., Anderson, V. L., Robertson, E. J., Secombes, C. J., and van West, P. 2008. New insights into animal pathogenic oomycetes. Trends Microbiol. 16:13-19.

138. R Development Core Team. 2011. R: A Language and Environment for Statistical Computing. R Foundation for Statistical Computing, Vienna, Austria.

139. Rafin, C., Brygoo, Y., and Tirilly, Y. 1995. Restriction analysis of amplified ribosomal DNA of Pythium spp. isolated from soilless culture systems. Mycol. Res. 99:277-281

140. Rafin, C., Nodet, P., and Tirilly, Y. 1994. Immuno-enzymatic staining procedure for Pythium species with filamentous non-inflated sporangia in soilless cultures. Mycol.Res. 98:535-541.

141. Rey, P., Floch, G. 1., Benhamou, N., Salerno, M. I., Thuillier, E., and Tirilly, Y. 2005. Interactions between the mycoparasite Pythium oligandrum and two types of sclerotia of plant pathogenic fungi. Mycol. Res. 109:779-788.

142. Riethmüller, A., Weiß, M., and Oberwinkler, F. 1999. Phylogenetic studies of Saprolegniomycetidae and related groups based on nuclear large subunit ribosomal DNA sequences. Can. J. Bot. 77:1790-1800. 


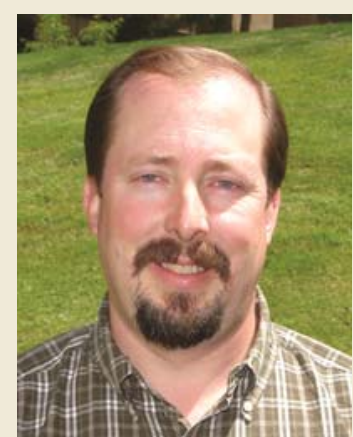

Kurtis L. Schroeder

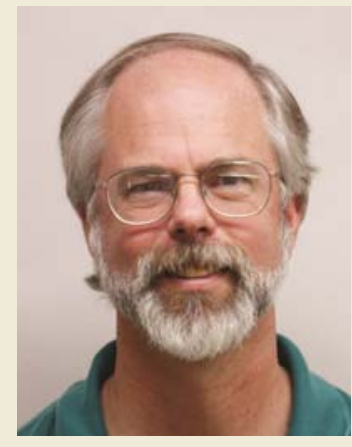

Frank N. Martin

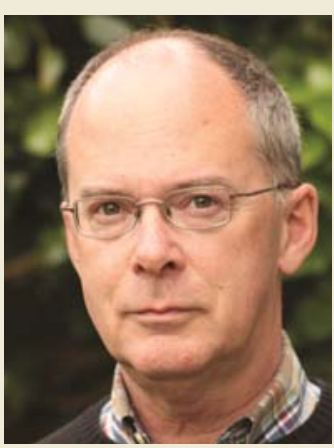

Arthur W. A. M. de Cock

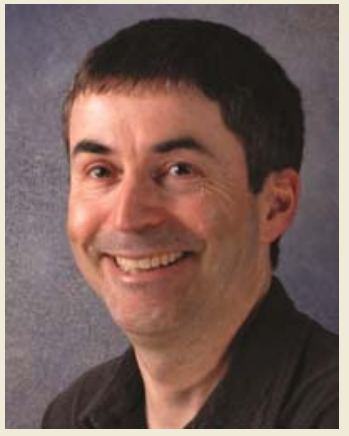

C. André Lévesque

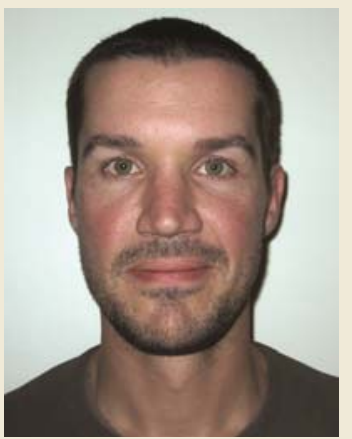

Christoffel F. J. Spies

Dr. Schroeder is a postdoctoral research associate in the Department of Plant Pathology at Washington State University. He received a B.S. in microbiology and an M.S. in plant science from the University of Idaho, and a Ph.D. in plant pathology from Washington State University, where his research focused on understanding the impact of transitioning to direct seeding on soilborne pathogens of wheat and barley. His research focuses on studying the ecology and molecular characterization of populations of soilborne pathogens, specifically Pythium, Rhizoctonia, and Fusarium spp. This includes work on molecular identification and quantification of these species from environmental samples as well as studying disease management strategies for these fungi on cereals.

Dr. Martin has been a research plant pathologist with the USDA-ARS in Salinas, CA since 1996. He received his Ph.D. in plant pathology from the University of California, Berkeley and was with the Plant Pathology Department at the University of Florida for 10 years prior to his current position. His research has focused on the ecology, biology, detection, identification, and phylogeny of the genera Pythium and Phytophthora.

Dr. de Cock obtained his M.S. (biology, 1974) and Ph.D. (1980) at the University of Nijmegen, The Netherlands. In 1982, he joined the Centraalbureau voor Schimmelcultures (now CBSKNAW Fungal Biodiversity Centre) to become the specialist for the taxonomic group of Oomycetes. Since then, his main field of research has been the morphological and molecular taxonomy of Pythium and Phytophthora. In 1987, he was awarded a fellowship of the Alexander von Humboldt Foundation. From October 1987 to 1989 , he worked in the Department of Molecular Genetics, Gesellschaft für Strahlen- und Umweltforschung (GSFMünchen), Göttingen, Germany. In these years, he studied the molecular taxonomy of Phytophthora. Back in The Netherlands, he was housed in the yeast department of the CBS in Delft and contributed to the research on yeasts and yeast-like fungi, next to his Oomycete research. In the year 2000, the CBS moved to Utrecht where the yeast and fungal departments were combined. Since 2011, he has been curator of MycoBank, a database of fungal nomenclature.

Dr. Lévesque is a research scientist with the Biodiversity group of Agriculture and Agri-Food Canada, Ottawa, and is the study co-leader for the mycology/microbiology unit. $\mathrm{He}$ is

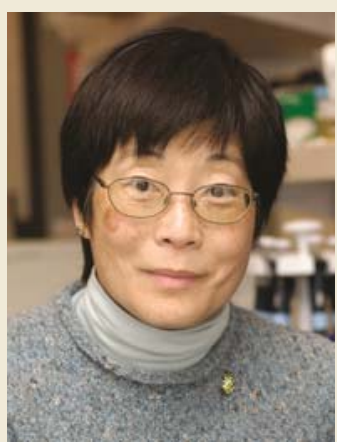

Patricia A. Okubara

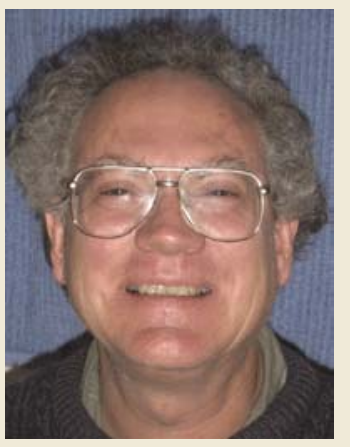

Timothy C. Paulitz adjunct professor in the Biology Department of Carleton University, Ottawa. He graduated with a B.S. in agriculture from McGill University, Montréal, a Master of Pest Management (1985) and Ph.D. (1990) degrees in plant pathology from Simon Fraser University, Burnaby, British Columbia. He was president of the Canadian Phytopathological Society in 2005 to 2006. His current research is on molecular taxonomy and ecology of fungi, specializing on zoosporic fungi and oomycetes. Lately, he has been involved in genomics of Pythium in collaboration with $\mathrm{C}$. Robin Buell of Michigan State University.

Dr. Spies is a postdoctoral researcher at Agriculture and AgriFood Canada in Ottawa. He earned his B.S. degree in genetics and plant pathology and M.S. and Ph.D. degrees in plant pathology at the University of Stellenbosch, South Africa. His research at the University of Stellenbosch focused on molecular detection and characterization of Pythium and Phytophthora species associated with grapevines and citrus. He is currently involved in taxonomic investigations of oomycetes with emphasis on Pythium and closely related genera.

Dr. Okubara is a USDA-ARS research geneticist and adjunct faculty in the Plant Pathology and Molecular Plant Sciences graduate programs at Washington State University, Pullman. She earned a B.S. in biochemistry from the University of California, Davis, and a Ph.D. in biology from the University of California, Los Angeles. Her research focuses on molecular wheat-microbe interactions, including root defense pathways, molecular diagnostics of soilborne pathogens and pests, and genomics of root-interacting fungi and bacteria.

Dr. Paulitz has been a research plant pathologist with the USDA-ARS in Pullman, WA since 2000. He was a professor at Macdonald Campus of McGill University in Ste. Anne de Bellevue, Québec, Canada for 10 years, and also did postdoctoral work at USDA-ARS in Corvallis, OR and Colorado State University, Ft. Collins. He received his Ph.D. from the University of California, Riverside. He investigates root diseases and soilborne pathogens of wheat, barley, Brassicas, and other rotation crops, with an emphasis on Rhizoctonia, Pythium, Fusarium, and nematode diseases. He focuses on the ecology, epidemiology, spatial analysis, and molecular detection and quantification of soilborne pathogens, and the development of cultural management techniques for root diseases, especially in direct-seed no-till systems. 
143. Rintoul, T., Eggertson, Q., and Lévesque, C. A. 2011. Multigene phylogenetic analyses to delimit new species in fungal plant pathogens. In: Plant Fungal Pathogens: Methods and Protocols. M. D. Bolton and B. P. Thomma, eds. Humana Press, New York.

144. Robideau, G. P., De Cock, A. W. A. M., Coffey, M. D., Voglmayr, H., Brouwer, H., Bala, K., Chitty, D. W., Desaulniers, N., Eggertson, Q. A., Gachon, C. M. M., Hu, C. H., Kupper, F. C., Rintoul, T. L., Sarhan, E., Verstappen, E. C. P., Zhang, Y., Bonants, P. J. M., Ristaino, J. B., and Lévesque, C. A. 2011. DNA barcoding of oomycetes with cytochrome c oxidase subunit I and internal transcribed spacer. Mol. Ecol. Resour. 11:1002-1011

145. Roze, E., and Cornu, M. 1869. Sur deux nouveaux types génériques pour les familles des Saprolégniées et Péronosporées. Annls Sci. Nat., Bot, Sér. 11:72-91.

146. Rumberger, A., Merwin, I. A., and Thies, J.-E. 2007. Microbial community development in the rhizosphere of apple trees at a replant disease site. Soil Biol. Biochem. 39:1645-1654.

147. Schroeder, K. L., Okubara, P. A., Tambong, J. T., Lévesque, C. A., and Paulitz, T. C. 2006. Identification and quantification of pathogenic Pythium spp. from soils in eastern Washington using real-time polymerase chain reaction. Phytopathology 96:637-647.

148. Schroeder, K. L., and Paulitz, T. C. 2006. Quantification of Pythium species in soils from dryland cereal-based cropping systems using realtime PCR. (Abstr.) Phytopathology 96:S105.

149. Schröter, J. 1893. Pythiaceae. Engler \& Prantl, nat. Pfl. Fam. 1:104-105.

150. Schurko, A. M., Mendoza, L., Lévesque, C. A., Désaulniers, N. L., De Cock, A. W. A. M., and Klassen, G. R. 2003. A molecular phylogeny of Pythium insidiosum. Mycol. Res. 107:537-544.

151. Scott, P. T., Martin, H. L., Boreel, S. M., Wearing, A. H., and Maclean, D. J. 2005. Molecular characterisation, pathogenesis and fungicide sensitivity of Pythium spp. from table beet (Beta vulgaris var. vulgaris) grown in the Lockyer Valley, Queensland. Australas. Plant Pathol. 34:361-368.

152. Sekimoto, S., Hatai, K., and Honda, D. 2007. Molecular phylogeny of an unidentified Haliphthoros-like marine oomycete and Haliphthoros milfordensis inferred from nuclear-encoded small- and large-subunit rRNA genes and mitochondrial-encoded cox2 gene. Mycoscience 48:212-221.

153. Sekimoto, S., Yokoo, K., Kawamura, Y., and Honda, D. 2008. Taxonomy, molecular phylogeny, and ultrastructural morphology of Olpidiopsis porphyrae sp. nov. (Oomycetes, straminipiles), a unicellular obligate endoparasite of Bangia and Porphyra spp. (Bangiales, Rhodophyta). Mycol. Res. 112:361-374

154. Sparrow, F. K. 1931. The classification of Pythium. Science, N. Y. 73:4142.

155. Spenlinhaur, T. R., Judice, S., Lampton, P., Hardingham, J., Estock, M., Kovacs, S., Hoyos, G., McFadd, T. K., and Parker, B. O. 2011. The use of isothermal DNA amplification (NEAR) in plant disease diagnostics. (Abstr.) Phytopathology 101:S215.

156. Spies, C. F. J., Mazzola, M., Botha, W. J., Langenhoven, S. D., Mostert, L., and McLeod, A. 2011. Molecular analyses of Pythium irregulare isolates from grapevines in South Africa suggest a single variable species. Fungal Biol. 115:1210-1224.

157. Spies, C. F. J., Mazzola, M., Botha, W. J., Van Der Rijst, M., Mostert, L., and McLeod, A. 2011. Oogonial biometry and phylogenetic analyses of the Pythium vexans species group from woody agricultural hosts in South Africa reveal distinct groups within this taxon. Fungal Biol. 115:157-168.

158. Spies, C. F. J., Mazzola, M., and McLeod, A. 2011. Characterisation and detection of Pythium and Phytophthora species associated with grapevines in South Africa. Eur. J. Plant Pathol. 131:103-119.

159. St. Laurent, A., Merwin, I. A., and Thies, J. E. 2008. Long-term orchard groundcover management system affect soil microbial communities and apple replant disease severity. Plant Soil 304:209-225.

160. Suffert, F., and Guibert, M. 2007. The ecology of a Pythium community in relation to the epidemiology of carrot cavity spot. Appl. Soil Ecol. 35:488501.

161. Sugiyama, A., Vivanco, J. M., Jayanty, S. S., and Manter, D. K. 2010. Pyrosequencing assessment of soil microbial communities in organic and conventional potato farms. Plant Dis. 94:1329-1335.

162. Supabandhu, J., Fisher, M. C., and Vanittanakom, N. 2007. Polymorphic microsatellite markers for the human oomycete pathogen Pythium insidiosum. Mol. Ecol. Notes 7:1088-1090.

163. Takenaka, S., Sekiguchi, H., Nakaho, K., Tojo, M., Masunaka, A., and Takahashi, H. 2008. Colonization of Pythium oligandrum in the tomato rhizosphere for biological control of bacterial wilt disease analyzed by real-time PCR and confocal laser-scanning microscopy. Phytopathology 98:187-195

164. Tambong, J. T., de Cock, A. W. A. M., Tinker, N. A., and Lévesque, C. A. 2006. Oligonucleotide array for identification and detection of Pythium species. Appl. Environ. Microbiol. 72:2691-2706.

165. Tamura, K., Peterson, D., Peterson, N., Stecher, G., Nei, M., and Kumar, S. 2011. MEGA5: Molecular Evolutionary Genetics Analysis using
Maximum Likelihood, Evolutionary Distance, and Maximum Parsimony Methods. Mol. Biol. Evol. 28:2731-2739.

166. Thomas, S. H., Housley, J. M., Reynolds, A. N., Penczykowski, R. M. Kenline, K. H., Hardegree, N., Schmidt, S., and Duffy, M. A. 2011. The ecology and phylogeny of oomycete infections in Asplanchna rotifers. Freshwat. Biol. 56:384-394.

167. Tojo, M., Nakazono, E., Tsushima, S., Morikawa, T., and Matsumoto, N. 1998. Characterization of two morphological groups of isolates of Pythium ultimum var. ultimum in a vegetable field. Mycoscience 39:135-144.

168. Tomlinson, J. A., Dickinson, M., Hobden, E., Robinson, S., Giltrap, P. M. and Boonham, N. 2011. A five-minute DNA extraction method for expedited detection of Phytophthora ramorum following prescreening using Phytophthora spp. lateral flow devices. J. Microbiol. Methods 81:116120 .

169. Uzuhashi, S., Imazu, M., and Kakishima, M. 2009. Structure and organization of the rDNA intergenic spacer region in Pythium ultimum. Mycoscience 50:224-232.

170. Uzuhashi, S., Tojo, M., and Kakishima, M. 2010. Phylogeny of the genus Pythium and description of new genera. Mycoscience 51:337-365.

171. Uzuhashi, S., Tojo, M., Kobayashi, S., and Kakishima, M. 2009. Pythium apinafurcum: Its morphology, molecular phylogeny, and infectivity for plants. Mycoscience 50:281-290.

172. Vallance, J., Le Floch, G., Déniel, F., Barbier, G., Lévesque, C. A., and Rey, P. 2009. Influence of Pythium oligandrum biocontrol on fungal and oomycete population dynamics in the rhizosphere. Appl. Environ. Microbiol. 75:4790-4800.

173. Van der Plaats-Niterink, A. J. 1981. Monograph of the genus Pythium Studies in Mycology No. 21. Centraalbureau Voor Schimmelcultures, Baarn, The Netherlands.

174. Van der Plaats-Niterink, A. J. 1981. Proposal for the additional conservation of the generic name Pythium Pringsheim 1858 vs. Artotrogus Mont. apud Berk 1845. Taxon 30:336.

175. Vasseur, V., Rey, P., Bellanger, E., Brygoo, Y., and Tirilly, Y. 2005. Molecular characterization of Pythium group $\mathrm{F}$ isolates by ribosomal- and intermicrosatellite-DNA regions analysis. Eur. J. Plant Pathol. 112:301310

176. Villa, N. O., Kageyama, K., Asano, T., and Suga, H. 2006. Phylogenetic relationships of Pythium and Phytophthora species based on ITS rDNA, cytochrome oxidase II and beta-tubulin gene sequences. Mycologia 98:410-422.

177. Voglmayr, H., and Riethmüller, A. 2006. Phylogenetic relationships of Albugo species (white blister rusts) based on LSU rDNA sequence and oospore data. Mycol. Res. 110:75-85.

178. Wang, P. H., Boo, L. M., Lin, Y. S., and Yeh, Y. 2002. Specific detection of Pythium aphanidermatum from hydroponic nutrient solution by booster PCR with DNA primers developed from mitochondrial DNA. Phytoparasitica 30:473-485

179. Wang, P. H., and Chang, C. W. 2003. Detection of the low-germinationrate resting oospores of Pythium myriotylum from soil by PCR. Lett. Appl. Microbiol. 36:157-161.

180. Wang, P. H., Chung, C. Y., Lin, Y. S., and Yeh, Y. 2003. Use of polymerase chain reaction to detect the soft rot pathogen, Pythium myriotylum, in infected ginger rhizomes. Lett. Appl. Microbiol. 36:116-120.

181. Wang, P. H., Wang, Y. T., and White, J. G. 2003. Species-specific PCR primers for Pythium developed from ribosomal ITS1 region. Lett. Appl. Microbiol. 37:127-132.

182. Wang, P. H., and White, J. G. 1997. Molecular characterization of Pythium species based on RFLP analysis of the internal transcribed spacer region of ribosomal DNA. Physiol. Mol. Plant Pathol. 51:129-143.

183. Waterhouse, G. M. 1967. Key to Pythium Pringsheim, Mycological Paper No. 109. Commonwealth Mycological Institute, Kew, Surry, England.

184. Waterhouse, G. M. 1968. The genus Pythium Pringsheim, Mycological Paper 110. Commonwealth Mycological Institute Kew, Surrey, England.

185. Weiland, J. J., and Sundsbak, J. L. 2000. Differentiation and detection of sugar beet fungal pathogens using PCR amplification of actin coding sequences and the ITS region of the rRNA gene. Plant Dis. 84:475-482.

186. White, T. J., Bruns, T., Lee, S., and Taylor, J. 1990. Amplification and direct sequencing of fungal ribosomal RNA genes for phylogenetics. Pages 315-322 in: PCR Protocols, a Guide to Methods and Applications. M. A Innis, D. H. Gelfand, J. J. Sninsky, and T. J. White, eds. Academic Press, San Diego.

187. Wingfield, M. J. 2011. One fungus one name: A plant pathologist's view. IMA Fungus 2:39-40.

188. Yao, S., Merwin, I. A., Abawi, G.-S., and Thies, J.-E. 2006. Soil fumigation and compost amendment alter soil microbial community composition but do not improve tree growth or yield in an apple replant site. Soil Biol. Biochem. 38:587-599.

189. Yuen, G. Y., Xia, J. Q., and Sutula, C. L. 1998. A sensitive ELISA for Pythium ultimum using polyclonal and species-specific monoclonal antibodies. Plant Dis. 82:1029-1032. 